\title{
Hydraulic Hybrid Propulsion for Heavy Vehicles: Combining the Simulation and Engine-In-the-Loop Techniques to Maximize the Fuel Economy and Emission Benefits
}

\author{
Z. Filipi ${ }^{*}$ and Y.J. Kim² \\ 1 University of Michigan, 2031 W. E. Lay Automotive Lab, 1231 Beal Ave., Ann Arbor, Ml $48109-2133$ - USA \\ 2 General Motors Corp., GM Hybrid Powertrain Engineering, 3300 GM road, Milford, MI 48380 - USA \\ e-mail : filipi@umich.edu -young.1.kim@gm.com \\ *Corresponding author
}

Résumé - Propulsion hybride hydraulique des poids lourds : une approche alliant les techniques de simulation et d' « Engine-In-the-loop» (EIL) afin de maximiser les économies de carburant et les avantages en termes d'émissions - La situation énergétique mondiale, la dépendance du secteur des transports vis-à-vis des combustibles d'origine fossile et la nécessité d'une réponse rapide face au défi présenté par le réchauffement climatique fournissent une forte motivation pour le développement de moyens de propulsion véhiculaires économes. Pour les camions, cette tâche est particulièrement difficile à accomplir du fait d'importantes contraintes de taille et de poids. L'hybridation est la seule approche qui puisse déboucher sur des progrès importants à court et moyen termes. En particulier, la configuration "hybride série" découple le moteur thermique des roues et permet une flexibilité complète dans le contrôle des points de fonctionnement moteur. De plus, la conversion et le stockage de l'énergie hydraulique fournissent une densité de puissance et un rendement excellents. Le défi technologique tient à la faible densité d'énergie de l'accumulateur hydraulique, et met en avant l'importance particulière du développement du gestionnaire de l'énergie.

Il est communément admis qu'il faut maintenir le moteur au point de rendement maximum mais, si l'objectif ultime en terme énergétique consiste à optimiser drastiquement le rendement du moteur, ceci induit des phases transitoires fréquentes causant pour des moteurs diesels des effets opposés tant sur l'émission de particules que sur l'agrément de conduite.

Par conséquent, nous proposons une méthodologie pour le superviseur d'énergie d'un système hybride, qui prend en compte 2 objectifs : la réduction de consommation et la réduction des émissions polluantes. Les économies de carburant sont prises en compte par une approche fondée sur la simulation, alors que l'étude de l'impact des phases transitoires du moteur sur les émissions de particules, est fondée sur un dispositif expérimental combinant modèles temps réel et moteur réel - l'EIL (Engine-In-the-Loop). Le dispositif EIL confirme que le contrôle de la répartition énergétique thermique/hydraulique de l'état de charge des batteries (SOC) présente des avantages certains sur celui basé sur l'approche de contrôle type «bang-bang ». De plus, elle démontre la capacité de l'Hybride Hydraulique Série à améliorer de $72 \%$ les économies de carburant d'un camion de taille moyenne tout en réduisant les émissions de particules de $74 \%$ comparée á la référence conventionnelle sur le cycle de conduite urbain. 


\begin{abstract}
Hydraulic Hybrid Propulsion for Heavy Vehicles: Combining the Simulation and Engine-In-the-Loop Techniques to Maximize the Fuel Economy and Emission Benefits - The global energy situation, the dependence of the transportation sector on fossil fuels, and a need for a rapid response to the global warming challenge, provide a strong impetus for development of fuel efficient vehicle propulsion. The task is particularly challenging in the case of trucks due to severe weight/size constraints. Hybridization is the only approach offering significant breakthroughs in near and mid-term. In particular, the series configuration decouples the engine from the wheels and allows full flexibility in controlling the engine operation, while the hydraulic energy conversion and storage provides exceptional power density and efficiency. The challenge stems from a relatively low energy density of the hydraulic accumulator. This places particular emphasis on development of the supervisory controller. The conventional wisdom is to operate the engine at the "sweet spot", but the aggressive pursuit of engine efficiency as the sole objective can lead to frequent and rapid diesel engine transients, thus causing an adverse affect on the soot emissions and driver feel. Therefore, we propose a comprehensive methodology for considering a combined hybrid system fuel-economy and emissions objective. The fuel economy is addressed with the simulation-based approach, while investigating the impact of engine transients on particulate emission relies on the Engine-In-the-loop (EIL) capability. The EIL study confirms advantages of a modulated state-of-charge control over the thermostatic approach, and demonstrates the ability of the Series Hydraulic Hybrid to improve the fuel economy of the medium truck by $72 \%$, while reducing the particulate emission by $74 \%$ compared to the conventional baseline over the city driving schedule.
\end{abstract}

\section{INTRODUCTION}

Looming shortage of the global crude oil supplies and growing environmental concerns provide a strong impetus for developing fuel-efficient vehicle technologies. The transportation sector is under a particularly strong pressure, given its almost exclusive dependence on fossil fuels [1]. The expected explosive economic growth in Asia, particularly China and India, is accelerating the rate of increasing fuel demand and intensifying pressure on the fuel supply side. While alternative fuels, such as the biofuels and synthetic fuels (made from natural gas or coal) hold a promise of providing some relief, improved fuel efficiency and conservation remain the best "new sources" of energy in the short to mid term. In addition, reduced fuel consumption directly benefits the efforts to reduce the Green House Gas (GHG) emissions, since combustion is a critical source of anthropogenic $\mathrm{CO}_{2}$ emissions.

Examination of the vehicle losses and options for improving the fuel economy reveals special challenges in the case of heavy vehicles. While in the passenger cars it is often possible to address all sources of losses, e.g. the fuel energy converter efficiency, vehicle mass, rolling resistance and air drag [2], the choices become severely limited in the case of trucks. Truck weight is dictated by the per-axle load limits, and implementation of light weight structures is likely to increase the payload carrying capacity, rather than reduce the gross vehicle weight. The size and shape of the payload carrying compartment diminish the chances for reducing the aerodynamic drag. Finally, the heavy trucks use highly efficient diesel engines and alternatives for tangible improvements of fuel conversion efficiency, while preserving the power- density, are not in sight. Therefore, hybridization is the only approach that promises significant improvements of the heavy-vehicle fuel economy, primarily through regeneration, optimization of engine operation and engine shut-downs.

A large mass of heavy trucks translates into high amounts of kinetic energy; hence, the rates of energy flow through the heavy-vehicle system during accelerations/decelerations are extremely high. This has proven to be an issue for Hybrid Electric Vehicles (HEV), particularly related to the energy storage. The batteries rely on chemical processes for energy storage, and the time-scales of these processes impose a constraint when it comes to frequent and rapid chargingdischarging schedules. Battery overheating often reduces the regeneration capacity under practical conditions. The alternative of using ultra-capacitors [3] is receiving considerable attention, but their cost, environmental challenges and charge leakage when the vehicle is parked, continue to be an issue. Consequently, the application of hydraulic devices for hybridization of heavy vehicles provides a very competitive option.

Hydraulics are characterized by inherently high-power density and comparatively high-energy conversion efficiency. The specific power density of the Pump/Motor (P/M) is an order of magnitude higher than that of the electric generator/motor [4]. The state-of-the-art bladder type accumulators with elastomeric foam reach round-trip efficiency of 95\% [5], and they accept exceptionally high rates of charging and discharging. A combination of high efficiency and high charging/discharging rates facilitates effective regeneration and re-use of energy in a heavy vehicle [6-9]. However, unique challenges are created by the relatively low rated 
speed encountered with traditional hydraulic pump-motor designs, and the relatively low energy density of the hydraulic accumulator. These drawbacks need to be addressed with optimized design and carefully tailored hybrid system supervisory control $[8,10]$, hence part of the motivation for this work. Additional motivation stems from a desire to gain insight into the low-emission capability of the series hydraulic hybrid system, and develop tools for simultaneous minimization of the fuel consumption and exhaust emission.

Our study focuses on a Series Hydraulic Hybrid Vehicle (SHHV) with a $4 \times 4$ driveline intended for both the on- and off-road use. The baseline vehicle specifications correspond to the High-Mobility Multipurpose Wheeled Vehicle (HMMWV or HUMMER), but the standard engine is replaced with a modern, higher output V8 6-Liter DI diesel engine. The layout of the baseline conventional propulsion system is shown in Figure 1a. The mechanical connection between the engine and the wheels has been removed in a series hybrid system. The desire to maximize the flexibility in operating and packaging the system led to a decision to implement two propulsion motors, one per axle (see Fig. $1 b$ ). The basic tool for the SHHV system analysis is a complete vehicle simulation in SIMULINK, or a "virtual vehicle". The components are represented with the physics-based models for maximum predictiveness and realistic scaling. The system integration in SUMULINK enables easy reconfiguration and facilitates design optimization and controller development.

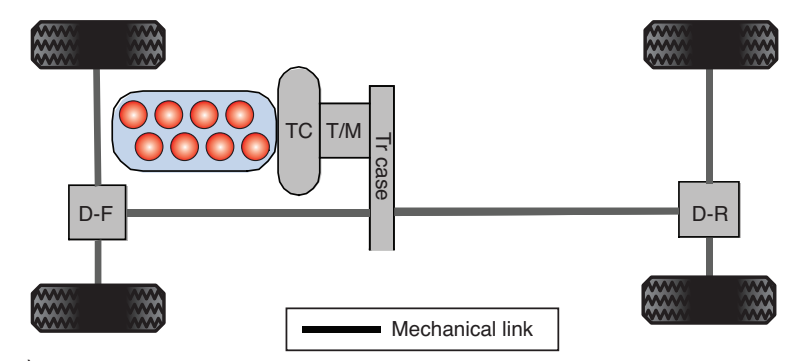

a)

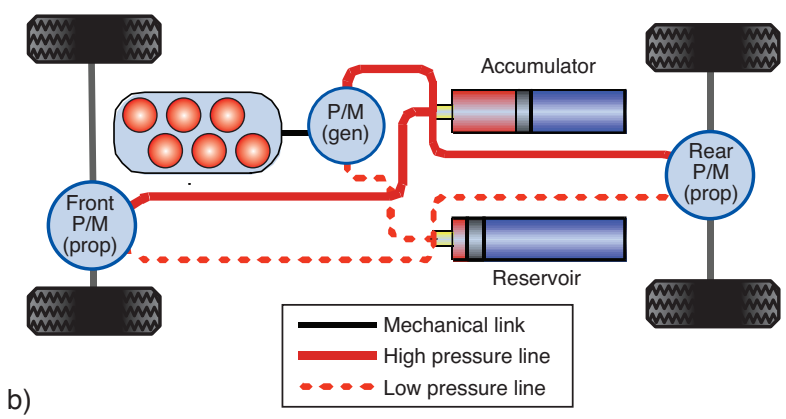

Figure 1

Propulsion system configuration for a $4 \times 4$ vehicle: a) Conventional, and b) Series Hydraulic Hybrid System.
The SHHV simulation is utilized to study the modes of operation in a $4 \times 4$ configuration and quantify the potential benefits of sequential motor operation. Next, the virtual SHHV is coupled to the optimization framework to determine the best combination of the design parameters, such as component sizes, gear ratios etc. In the third stage, the simulation is utilized to develop the supervisory control strategy and assess its impact on the interactions in the system. Our initial experience with the series HHV challenged the notion that running the engine at the "efficiency sweat spot" is the best for the vehicle fuel economy [11], therefore we investigate modulated State-Of-Charge (SOC) control as an alternative to the thermostatic, or "bang-bang" strategy. Finally, the Engine-In-the-Loop (EIL) facility [12] is brought into the fold to investigate the behavior of the real diesel engine system, including its external components and actuators, coupled to a virtual driveline/vehicle and assess the low-emission potential of the hydraulic hybrid. Further discussion about the role of EIL in developing the SHHV system is provided in the subsequent paragraph, followed by the outline of the paper.

The diesel engine emissions are characterized by an infamous particulate- $\mathrm{NO}_{\mathrm{x}}$ tradeoff. That is to say, any simple measure that reduces $\mathrm{NO}_{\mathrm{x}}(e . g$. retarding the injection timing) leads to an increase of particulate emission and vice versa. In addition, published work provides evidence of the detrimental impact of harsh diesel engine transients on particulate (or soot) emissions [13-16]. In particular, recent EIL work with a conventional powertrain showed that the transient spikes of soot emission may be responsible for up to a half of the total emission over the city driving schedule [13]. The series hybrid configuration provides the ultimate flexibility in controlling the engine operation, but aggressive optimization for maximum fuel economy may lead to rapid changes of the engine command accompanied by a particulate emission penalty. Therefore, emissions generated under realistic in-vehicle conditions have to be investigated thoroughly in order to address the tighter emissions standards announced by the US Environmental Protection Agency (EPA) and its European Union counterpart for 2010 and beyond. If aftertreatment components are incorporated, such as the Diesel Particulate Filter (DPF), their loading and regeneration schedules will be significantly impacted by the engine-out emission and transient phenomena. Unfortunately, simulating soot formation processes in a diesel engine is prohibitively slow in the context of systems work, since it requires coupling of sophisticated Computational Fluid Dynamics (CFD) models and chemical kinetics $[17,18]$. Therefore, we develop the Engine-In-theLoop capability to accurately characterize the influence of the SHHV system design and control on engine-out emissions, since running the engine in the test cell enables accurate real-time diagnostics of soot and $\mathrm{NO}_{\mathrm{x}}$ emissions [12]. In other words, the EIL is viewed as an additional methodology 
essential for the hybrid system development and analysis, rather than the tool for calibration of engine controller maps. The insight generated with systematic EIL testing is utilized as direct guidance for development of vehicle-level strategies for maximizing the low-emission potential of the SHHV. Of course, EIL also provides a very reliable validation of the fuel economy predictions.

The paper begins with a high-level description of the SHHV configuration examined in this study, and the discussion of the modeling and integration approach. This is followed by a section devoted to the development of the EIL capability for the series HHV architecture, including the techniques for overcoming the challenges related to integration of major hardware (the engine) with a virtual vehicle system. Next, we explain the use of the simulation tool to address the first three steps in optimizing the system performance and fuel economy, namely the analysis of the impact of the sequential vs simultaneous operation of the propulsion motors, the optimal design, i.e. selection of the best combination of component sizes and other system design variables, and finally the supervisory controller development for best fuel economy. In the latter, we review the SHHV supervisory control options, and explain how the lessons learned with the thermostatic control strategy lead to consideration of a modulated control approach. This sets the stage for bringing the exhaust emissions into the SHHV design/control analysis by transitioning the work into the EIL facility. Particular attention is given to analysis of transient soot emission spikes observed during rapid increases of engine load and the use of the insight to improve the behavior of the system. Finally, the diagnostic capabilities of the EIL setup are utilized for characterizing the interactions in the system, validating the simulation predictions and quantifying both the fuel economy and the emission potential of the SHHV system for a medium truck. The paper ends with a brief discussion of the outlook and conclusions. We note here that more detailed discussions of the previous work by others are given in individual sections of the paper rather than in the introduction, so as not to burden the opening part with excess material and enable a clearer statement of the motivation and objectives.

\section{MODELING OF THE HYDRAULIC HYBRID PROPULSION SYSTEM}

The configuration of the $4 \times 4$ SHHV system with two propulsion motors modeled in this work is given in Figure $1 b$. The engine is connected to the $\mathrm{P} / \mathrm{M}_{\mathrm{gen}}$ to create a powergeneration subsystem capable of charging the accumulator and/or providing fluid under pressure to $\mathrm{P} / \mathrm{M}_{\text {prop }}-s$ for propulsion. The $\mathrm{P} / \mathrm{M}_{\mathrm{gen}}$ can be used as a motor to start the engine. The conventional driveline is completely removed and two pump/motors are connected to the front and rear wheel axles through a final gear and differentials. Operating the $\mathrm{P} / \mathrm{M}_{\text {prop }}$ in the Motor mode propels the vehicle, while regenerative braking requires switching to the Pump mode. If braking torque provided by hydraulics is not enough, it is supplemented by the frictional brake. A two-step gear box is applied between the $\mathrm{P} / \mathrm{M}_{\text {prop }}$ and the wheels to prevent the motor from overspeeding, multiply the torque at launch and enable placing the motor into an efficient load/speed region. The accumulator stores the energy and ensures a continuous supply of pressurized fluid under any conditions. This section describes the approach to modeling the main components in the hydraulic hybrid powertrain and subsequent integration into a complete series hydraulic hybrid vehicle.

\subsection{Modeling the Components and Subsystems}

The engine module takes the load command from the supervisory controller and external load as inputs, and calculates engine speed response and fuel consumption. The model includes an engine torque map, a fuel controller with speed-governing functions and engine dynamics. The lookup table providing brake torque as a function of instantaneous engine speed and mass of fuel injected is generated from experimental data obtained in the W. E. Lay Automotive Laboratory at the University of Michigan using a fully instrumented Navistar V8 6L turbocharged diesel [12]. The diesel engine specifications are listed in the Appendix. The highfidelity modeling alternative is available too, in case the study requires in-depth analysis of engine processes [19]. However, as stated in the introduction, analysis of exhaust emission during transient operation still requires experimentation, hence we opted to invest effort into developing the Engine-In-the-Loop capability rather than attempt addressing soot emission with simulation work.

The diesel engine fuel-injection controller provides the signal for the mass of fuel injected per cycle based on driver (or supervisory controller) command and current engine speed. The turbo-lag period is studied in the test cell first, and the data are subsequently used to calibrate the time delay incorporated in the injection controller. This adds intelligence to the controller and allows capturing the effect of turbo-lag on diesel engine transient torque-response. The rate of change of engine speed is calculated from the difference between the brake torque and load torque provided by the $\mathrm{P} / \mathrm{M}_{\text {gen }}$ submodel, and the sum of pump and engine inertia. When varying the size of the engine, it is assumed that the new engine retains the same design features, combustion chamber design etc., thus ensuring full similitude. More details can be found in Filipi et al. [8].

The hydraulic pump/motor model is an updated version of Wilson's P/M theory [20]. The P/M is an axial piston variable displacement type. The torque and hydraulic fluid flow are controlled by displacement factor. Details of the model are provided in Filipi et al. [10] and Kim et al. [11]. Nevertheless, the key equations are reviewed here in order to 
provide foundation for discussion about the inverse model necessary for developing the Engine-In-the-Loop capability.

Ideal leak-free volumetric flow rate of $\mathrm{P} / \mathrm{M}$ is:

$$
Q_{i}=x \omega D
$$

Ideal frictionless torque of $\mathrm{P} / \mathrm{M}$ is:

$$
T_{i}=x \Delta p D
$$

where $x$ is displacement factor, and its sign is negative for pump operation and positive for motor operation; $\omega$ is angular velocity $(\mathrm{rad} / \mathrm{s}) ; D$ is maximum $\mathrm{P} / \mathrm{M}$ displacement per radian $\left(\mathrm{m}^{3} / \mathrm{rad}\right)$; and $\Delta p$ is a pressure difference across the machine $(\mathrm{Pa})$.

The difference between actual and ideal volumetric flow $\left(\mathrm{m}^{3} / \mathrm{s}\right)$ determines the volumetric efficiency:

$$
\begin{aligned}
& \eta_{v, \text { pump }}=\frac{Q_{a}}{Q_{i}}=1-\frac{C_{s}}{|x| S}-\frac{\Delta p}{\beta}-\frac{C_{s t}}{|x| \sigma} \\
& \eta_{v, \text { motor }}=\frac{Q_{i}}{Q_{a}}=\frac{1}{1+\frac{C_{S} S}{|x|}+\frac{\Delta p}{\beta}+\frac{C_{s t}}{|x| \sigma}}
\end{aligned}
$$

where $\frac{C_{s}}{|x| S}, \frac{\Delta p}{\beta}$ and $\frac{C_{s t}}{|x| \sigma}$ represent laminar leakage loss, compressibility and turbulent leakage loss, respectively. $\beta$ is oil bulk modulus of elasticity $(\mathrm{Pa})$, and $S \equiv \frac{\mu \omega}{\Delta p}$ and

$$
\sigma \equiv \frac{\omega D^{1 / 3}}{\left(2 \frac{\Delta p}{\rho}\right)^{1 / 2}}
$$

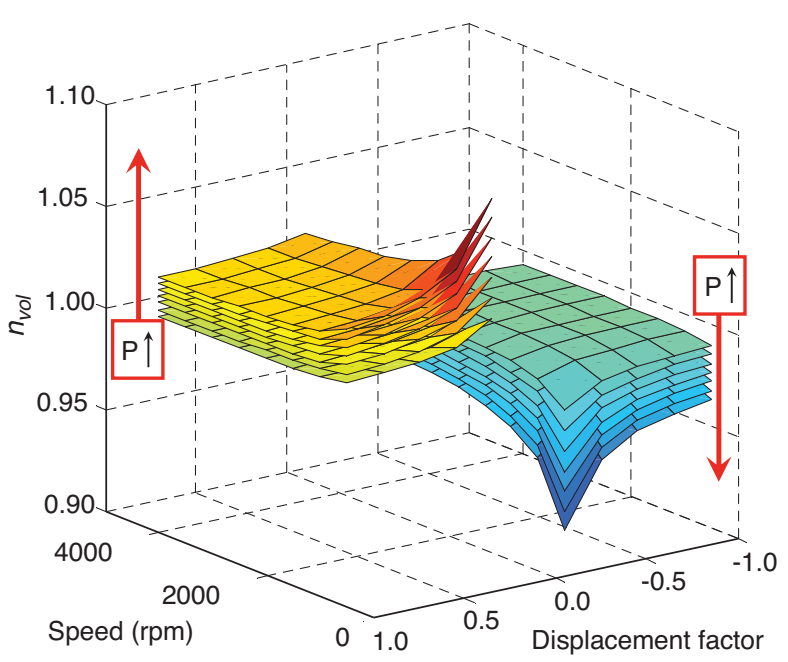

Figure 2

Variations of the pump and motor volumetric efficiency as a function of "load" (i.e. displacement factor), speed and pressure difference across the machine. are dimensionless numbers in which $\rho$ is oil density $\left(\mathrm{kg} / \mathrm{m}^{3}\right)$ and $\mu$ is oil dynamic viscosity $\left(\mathrm{Ns} / \mathrm{m}^{2}\right)$.

Torque efficiency relates actual and ideal torque:

$$
\begin{aligned}
& \eta_{t, \text { pump }}=\frac{T_{i}}{T_{a}}=\frac{1}{1+\frac{C_{v} S}{|x|}+\frac{C_{f}}{|x|}+C_{h} x^{2} \sigma^{2}} \\
& \eta_{t, \text { motor }}=\frac{T_{a}}{T_{i}}=1-\frac{C_{v} S}{|x|}-\frac{C_{f}}{|x|}-C_{h} x^{2} \sigma^{2}
\end{aligned}
$$

where $\frac{C_{v} S}{|x|}, \frac{C_{f}}{|x|}$ and $C_{h} x^{2} \sigma^{2}$ represent the viscous loss, the mechanical friction and the hydrodynamic loss, respectively.

The coefficients, which are used for calculation of volumetric and torque efficiencies, are calibrated to match the particular P/M developed for propulsion [7]. The terms in the models of losses have physical meaning. Therefore, once the coefficients are calibrated, the predictions capture the effects of physical parameters, such as the displacement factor or the pressure difference, on pump/motor efficiency. This is extremely important in the system optimization studies, as the interactions dictated by matching of components and the control strategy may lead to very different operating regimes. An example of the dependency of the volumetric efficiency on "load", i.e. the displacement factor, speed and pressure are given in Figure 2, and the similar graph depicting the variations of the torque efficiency is shown in Figure 3. The torque efficiency is obviously more relevant, since volumetric efficiency remains much higher throughout

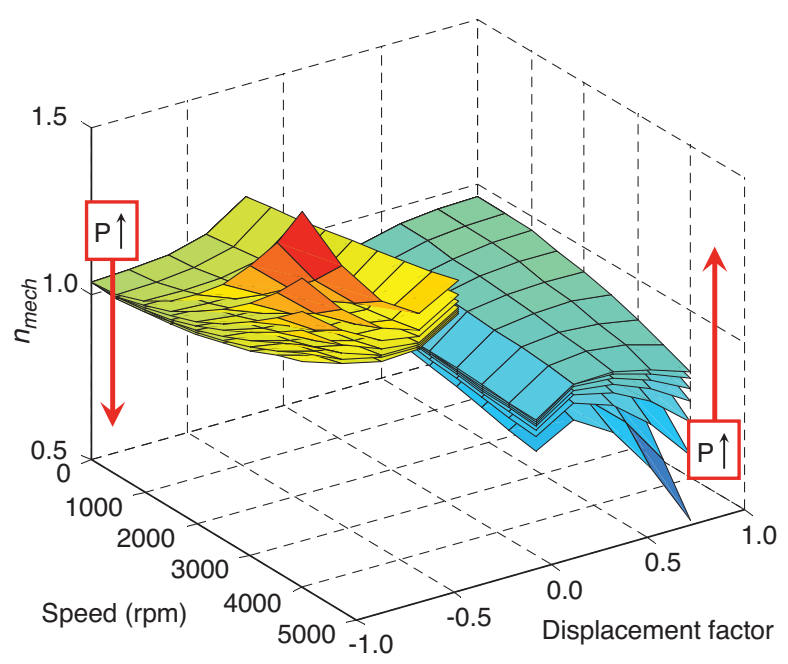

Figure 3

Variations of the pump and the motor torque efficiency as a function of "load" (i.e. displacement factor), speed and pressure difference across the machine. 
the range. The surfaces in the area $<1$ depict the trends for the motor. The displacement factor obviously has a very strong effect on the efficiency, with maximum corresponding to high loads. The increase in speed generally reduces the efficiency. Finally, the trends with pressure are relatively complex, given its impact on both the individual losses and the pump/motor output. Generally, the increase in pressure benefits the torque efficiency and has a detrimental effect on volumetric efficiency (due to increased leakage).

The hydro-pneumatic accumulator provides energy storage. As the pump transfers the hydraulic fluid into the accumulator, the pressure of the gas sealed inside of it increases, thus storing energy. The typical design of the bladder-type accumulator is shown in Figure 4. Since the fluid is transferred through the system during every charging/discharging event, a low pressure reservoir is required too (see Fig. 1b). The pressure in the reservoir is much lower, consequently it does not significantly affect the overall energy flows. Maintaining some level of pressure in the reservoir is beneficial for prevention of the cavitation in the pump. The pressure difference between accumulator and reservoir determines the maximum motor torque. The modern light-weight accumulators are often built using the carbon-fiber shell, and they can be pressurized up to $50 \mathrm{MPa}$. However, safety concerns and risk of leaks from other components, such as the valves and fittings, often limit the pressure in the practical system to 35 40 MPa.

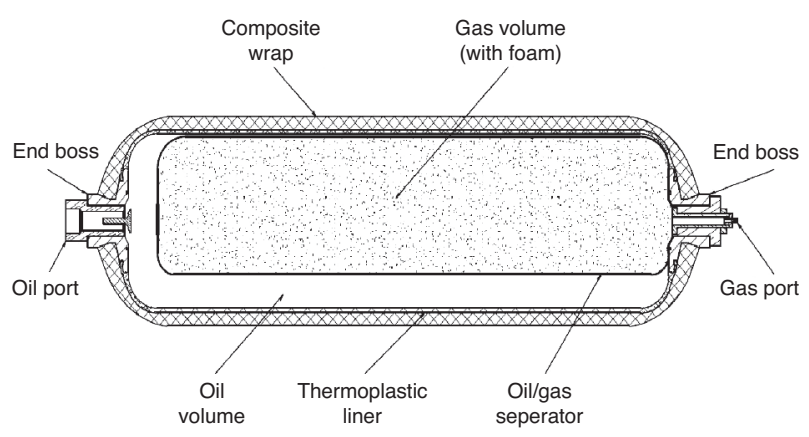

Figure 4

Typical bladder-type accumulator. The gas is inside the bladder, and the hydraulic fluid surrounds it, from [7].

Modeling of the accumulator and the reservoir is based on the application of the energy conservation equation to the gas, as proposed by Otis and Pourmovahed [20, 21]. The derivation starts with the formulation of the equation for the ideal gas, but the real gas properties are introduced in the final step due to high-peak pressures typically experienced in real devices. The complete formulas are omitted here, and are available in $[10,21]$. However, we point out the main lesson learned from the high-fidelity, thermodynamic modeling of

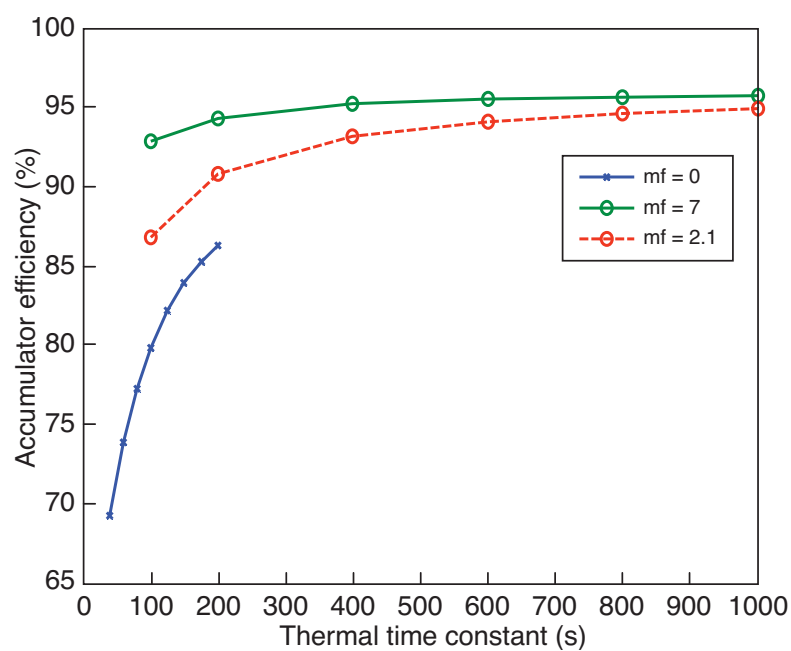

Figure 5

The sensitivity of the accumulator efficiency to the thermal time-constant and the effect of adding elastomeric foam to the gas-side of the $86 \mathrm{~L}$ accumulator. The blue solid line indicates variations of efficiency in the standard accumulator without foam, the effect of adding a $2.1 \mathrm{~kg}$ of foam is shown in red, and the effect of adding $7 \mathrm{~kg}$ of foam is shown with the green line.

the accumulator: its round trip efficiency depends directly on the thermal time constant $\tau \equiv \frac{m_{g} c_{v}}{h A_{w}}$. In other words, the efficiency increases with higher thermal capacity, and lower heat loss. This realization led to the idea of adding elastomeric foam to the gas-side in order to significantly increase the thermal capacity $[22,23]$. The graph in Figure 5 illustrates these points. There are limits to how much can be done to increase the thermal time-constant of the standard accumulator, while adding elastomeric foam easily pushes the efficiency into the $\sim 95 \%$ region. The model in this study assumes $7 \mathrm{~kg}$ of foam added to the $86 \mathrm{~L}$ accumulator.

The mass of gas is directly related to the gas pressure range for a given accumulator size. In this study the gas mass is chosen to provide pre-charge pressure of $12.5 \mathrm{MPa}$ and maximum pressure of $35 \mathrm{MPa}$. The SOC is defined as the ratio of instantaneous fluid volume in the accumulator over the maximum fluid capacity. In real vehicle application, the pressure may be used as an indicator of the SOC, as long as the temperature variations are kept low by increasing the thermal capacity of the charge.

\subsection{Integrated Vehicle System Simulation}

The baseline vehicle is a conventional HMMWV model with a V8 engine. The complete forward looking vehicle system simulation is implemented in MATLAB/SIMULINK using the Vehicle Engine SIMulation (VESIM) platform previously 


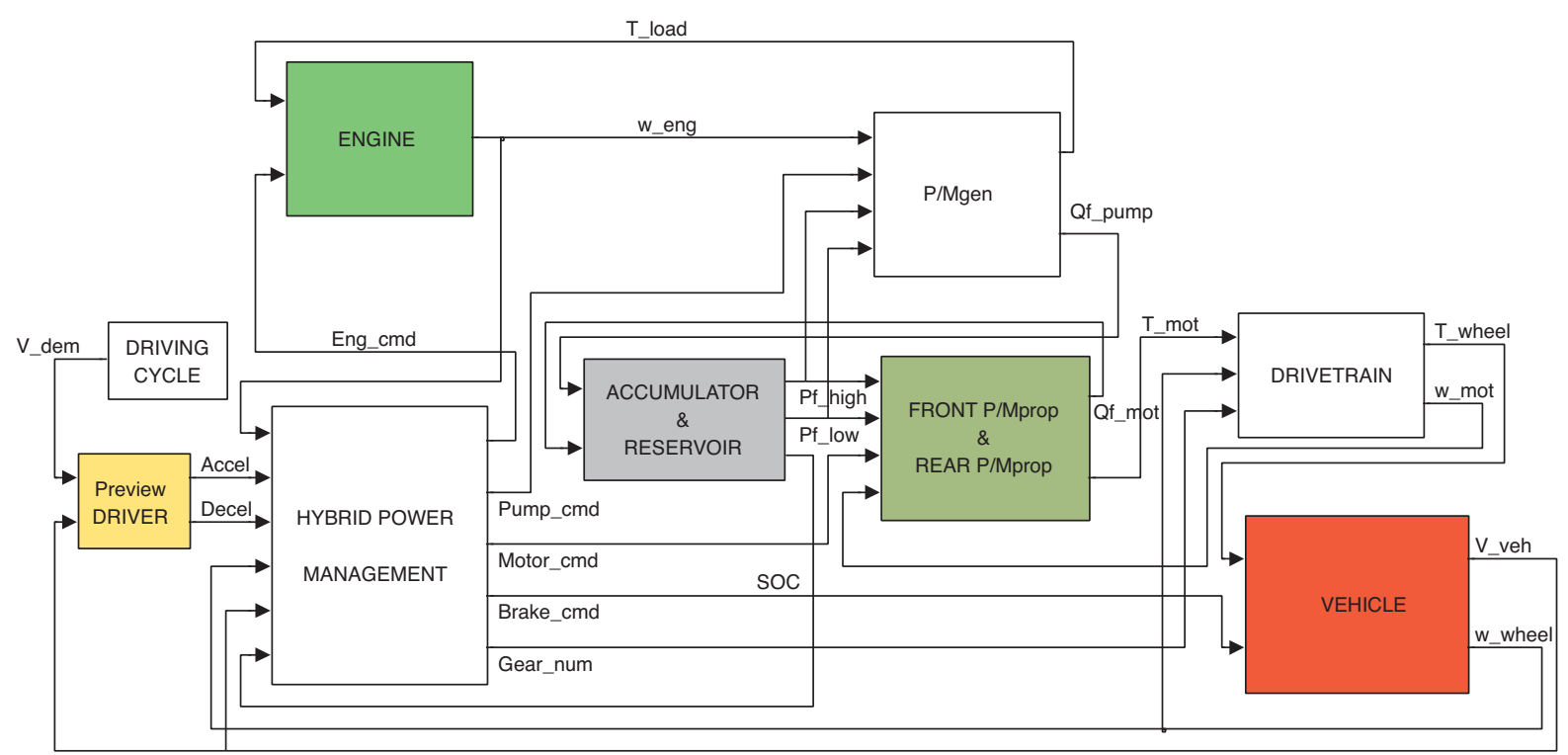

Figure 6

Integrated simulation of the series hydraulic hybrid vehicle in SIMULINK with a forward-looking logic.

developed by the researchers at the University of Michigan Automotive Research Center. The high fidelity VESIM model of a conventional truck has been validated by the vehicle test data measured on the proving ground [19] and it has subsequently been thoroughly updated to accurately represent the HUMMER driveline/vehicle using bond graphs by Louca et al. [24] and Fathy et al. [25].

Models of hydraulic components were first incorporated into VESIM in the context of parallel system power management studies $[8,9]$. This established the foundation for development of the SHH vehicle system simulation shown in Figure 6. In essence, the conventional driveline is removed and instead the hydraulic pump/motors are connected to front and rear differentials. A simple two-speed transmission is inserted in between to provide the required vehicles performance while maintaining motor speed below $4000 \mathrm{rpm}$. The hydraulic pump is mechanically coupled to the engine, and hydraulic lines are laid out between the hydraulic pump/motors, the accumulator and the reservoir.

The forward-looking logic is followed, thus mimicking the situation in the real vehicle. The cyber-driver sends a power-demand signal based on the prescribed driving schedule and the information about the current vehicle speed. This signal is processed in the supervisory controller and the appropriate commands are sent to the engine and hydraulic pump/motors. The engine operation is fully decoupled from the wheels, as the hydraulic $\mathrm{P} / \mathrm{M}_{\text {prop }}$ provides the required drive torque. Engine power command is determined based on the SOC in the accumulator, and its operation is optimized for best fuel efficiency - more information is given in the appropriate section of this paper. The summary of subsystem specifications is given in the Appendix.

\section{ENGINE-IN-THE-LOOP WITH A VIRTUAL VEHICLE}

Developing a modern propulsion system invariably entails some degree of prototyping. Simulation tools are indispensable for rapid prediction of vehicle behavior during a typical mission and evaluation and selection of propulsion concepts and components early in the design process $[8,10,11,19$, 26-34]. Simulation tools also make it possible to vary and optimize component and subsystem designs for given goals and constraints [35, 36]. However, simulation-based vehicle system design is not without limitations. Conducting vehiclelevel studies over complete driving schedules limits the degree of fidelity that can be afforded within a reasonable computational time frame. For instance, simulating soot formation processes in a diesel engine is prohibitively slow in the context of systems work, since it requires coupling of sophisticated Computational Fluid Dynamics (CFD) models and chemical kinetics. Therefore, even though state-of-the-art vehicle simulations enable assessing vehicle performance, fuel economy and dynamic response with high confidence, verification of emissions trends necessitates experimentation. Merging the virtual and real worlds, by combining physical engines with virtual drivelines and vehicles is the only way to accurately and comprehensively characterize the influence of system design on performance, fuel economy, and emissions early in the vehicle design cycle.

EIL setup couples a real engine with the "virtual vehicle", i.e. a simulation of the driveline and the vehicle. In contrast with more traditional implementation of the Hardware-Inthe-Loop (HIL) that typically features a control unit in hardware integrated with virtual devices and systems being controlled, a major piece of hardware is integrated with virtual 
devices emulating realistic operating conditions. Using the virtual driveline/vehicle simulation enables rapid prototyping, reliable validation of the SHHV simulation results and optimization of the design and supervisory control. Having the engine in the test cell enables application of advanced diagnostics and generating insight required for assessing the low-emission potential of a diesel-hybrid under realistic operating conditions. Consequently, our use of HIL simulation is not limited to control design, testing and calibration, but addresses broader objectives of evaluating an integrated hybrid powertrain system configuration. In this we differ from typical applications of HIL for controller design and engine calibration work [37,38], or for evaluation of individual components $[39,40]$ in the emulated vehicle.

\subsection{Engine Experimental Setup}

The engine used in this investigation is a 6 Liter V-8 directinjection diesel engine manufactured by the Navistar Corporation. The engine is intended for a variety of medium duty truck applications covering the range between US Classes IIB and VII. Replacing the standard 6.5 L turbocharged IDI engine developing $145 \mathrm{~kW}$ with the more powerful Navistar V8 engine creates a virtual "superHummer" capable of providing exceptional performance even in heavier versions of the vehicle. The specifications are listed in the Appendix.

The engine incorporates advanced technologies to provide high power density while meeting emissions standards. A Hydraulic Electronic Unit Injector (HEUI) system permits the precise control of fuel injection timing, pressure, and quantity, and furthermore allows the use of pilot injection.
An Exhaust Gas Recirculation (EGR) circuit is used to introduce cooled exhaust gases into the intake manifold in order to decrease $\mathrm{NO}_{\mathrm{x}}$ emissions. EGR flow rate is controlled through modulation of the EGR valve and the setting of the Variable Geometry Turbocharger (VGT). The VGT can also enhance engine performance, as it reduces turbo lag and allows control of the intake manifold pressure.

The engine is coupled to a $330 \mathrm{~kW}$ AVL ELIN series 100 APA Asynchronous Dynamometer. This dynamometer is especially suited to perform transient testing, as it has a $5 \mathrm{~ms}$ torque response time and a $-100 \%$ to $+100 \%$ torque reversal time of $10 \mathrm{~ms}$. Operation of the test cell is orchestrated via the AVL PUMA Open system, providing an environment for monitoring and controlling test cell functions. The engine is fully instrumented for time-based measurements of pressures, temperatures, and flow rates at various locations in the system. Crank-angle resolved measurements include in-cylinder pressure, fuel injection pressure and injector needle lift.

An AVL Combustion Emissions Bench (CEB-II) is used to sample, condition, and measure exhaust gas constituents. Analyzers measure the proportion of carbon monoxide (CO), carbon dioxide $\left(\mathrm{CO}_{2}\right)$, oxygen $\left(\mathrm{O}_{2}\right)$, total hydrocarbons (THC), and oxides of nitrogen $\left(\mathrm{NO}_{\mathrm{x}}\right)$ in the exhaust gas. $\mathrm{CO}_{2}$ levels in the intake manifold are also measured to quantify EGR rates. These analyzers do not have the response time necessary to accurately follow the instantaneous temporal dynamics of emissions pulses, but they do provide an accurate integrated response [41].

Accurate temporal measurement of transient $\mathrm{NO}_{\mathrm{x}}$ is provided by a CLD 500 Fast $\mathrm{NO}_{\mathrm{x}}$ analyzer made by Cambustion Ltd. It consists of a chemiluminescent detector with a $90 \%$ to $10 \%$ response time of less than $3 \mathrm{~ms}$ for NO,

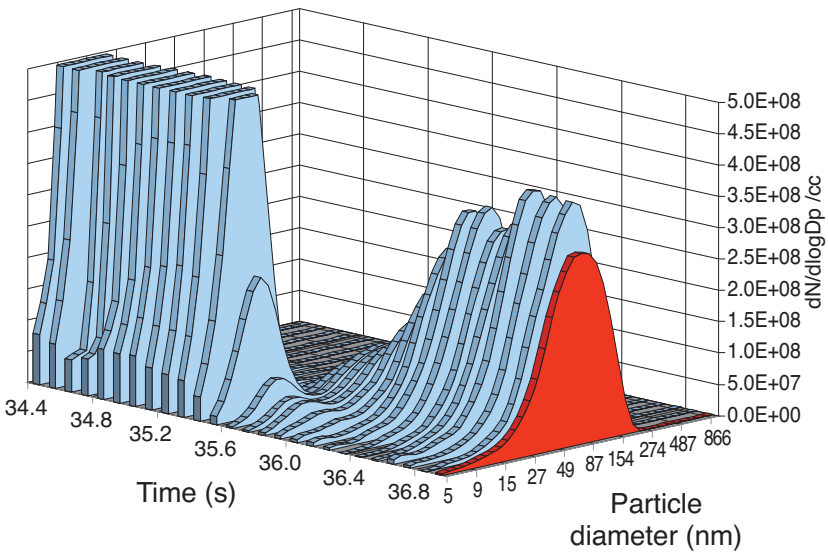

a)

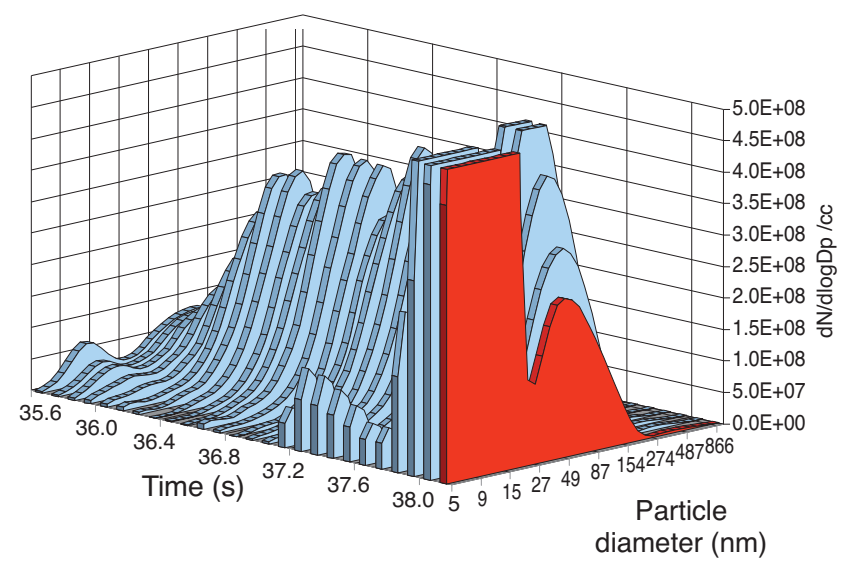

b)

Figure 7

Sequences of particle size-number distributions obtained with the Differential Mobility Spectrometer during a 30-46 s interval of the FTP 75 driving schedule in the conventional vehicle: a) interval capturing the beginning of the transient with a marked shift towards increased particle size at the onset of a load change, and b) interval capturing stabilization of engine operation at high load after the rapid transient, with a typical dual-mode profile - from [13]. 
and less than $10 \mathrm{~ms}$ for $\mathrm{NO}_{\mathrm{x}}$. This is achieved by locating the detectors in sample heads that are positioned very close to the sample point and using vacuum to convey the sample gas to the detectors through narrow heated capillaries.

Temporally resolved particulate concentrations are obtained using a Differential Mobility Spectrometer (DMS) 500 manufactured by Cambustion Ltd. This instrument measures the number of particles and their spectral weighting in the $5 \mathrm{~nm}$ to $1000 \mathrm{~nm}$ size range with a time response of $200 \mathrm{~ms}$. The DMS provides aerosol size spectral data by using a corona discharge to place a prescribed charge on each particle, and an array of electrodes in a classifier column to sort them based on the aerodynamic drag-to-charge ratio. Conversion of aerosol spectral size data into particulate mass is accomplished by using a relationship suggested by the manufacturer [42], based on results obtained from an SMPS (Scanning Mobility Particle Sizer) and an APM (Aerosol Particle Mass) Spectrometer and published by Park et al. [43]. While these instruments use the same principles to classify particles, they require much more time $(\sim 100 \mathrm{~s})$ to produce a full size spectrum. Ultimately, the particle size-number distributions are binned, the number of particles is converted to mass based on the relationship from [42], and masses per bin are summed up to get the total particulate mass per second in the exhaust stream. Our previous experience regarding the impact of rapid transients indicate a significant shift of profiles towards the larger size and consequently a large spike of particle emission after a rapid increase of engine command [13]. This is illustrated in Figure 7: the profiles indicating primarily the nano-particles $(10-30 \mathrm{~nm})$ during the low-load operation shift dramatically towards the 150 $\mathrm{nm}$ region at the initiation of a transient (see Fig. 7a), while stabilizing the engine at the high load causes the profiles to retreat back towards smaller sizes and display the expected dual-mode shape. This type of transient behavior is exactly what we aim to avoid by carefully designing the supervisory controller of the hybrid vehicle.

\subsection{EIL Integration and Challenges of Coupling the Engine with a Virtual Hydraulic Driveline}

Three methods for investigating in-vehicle engine behavior can be considered:

- instrument a vehicle and acquire data as it is driven on open roads;

- operate a vehicle on a chassis dynamometer over prescribed driving cycles;

- use a dynamometer to couple the engine with virtual dynamic models of the driver, driveline, and vehicle, then run the engine and virtual models concurrently in real time.

While each method has its benefits and drawbacks, option (3) is unique because it eliminates vehicle variability and situates the engine in a test cell, thereby allowing very detailed measurements in a controlled lab environment. Furthermore, it offers the flexibility of easily changing the configuration of the vehicle system and selection of virtual components, and that's of particular interest in the development and analysis of a hybrid propulsion system.

The prerequisites for developing the EIL capability are: a suite of real-time vehicle models with appropriate fidelity, the advanced highly-dynamic dynamometer, and a MATLABSIMULINK interface for linking the real and the virtual. The uncovered integration challenges and the solutions for development of the EIL setup for a conventional vehicle were described by Filipi et al. in [12]. An extensive review of previous efforts by others related to HIL and EIL methodologies are also provided in [12], and in [13]. To recapitulate, reversing

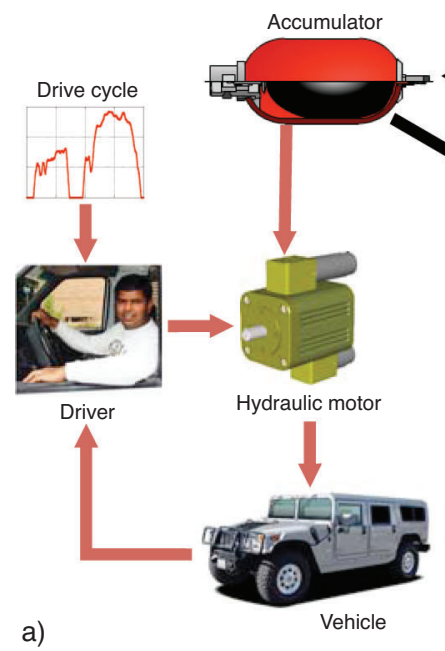

a)

Figure 8

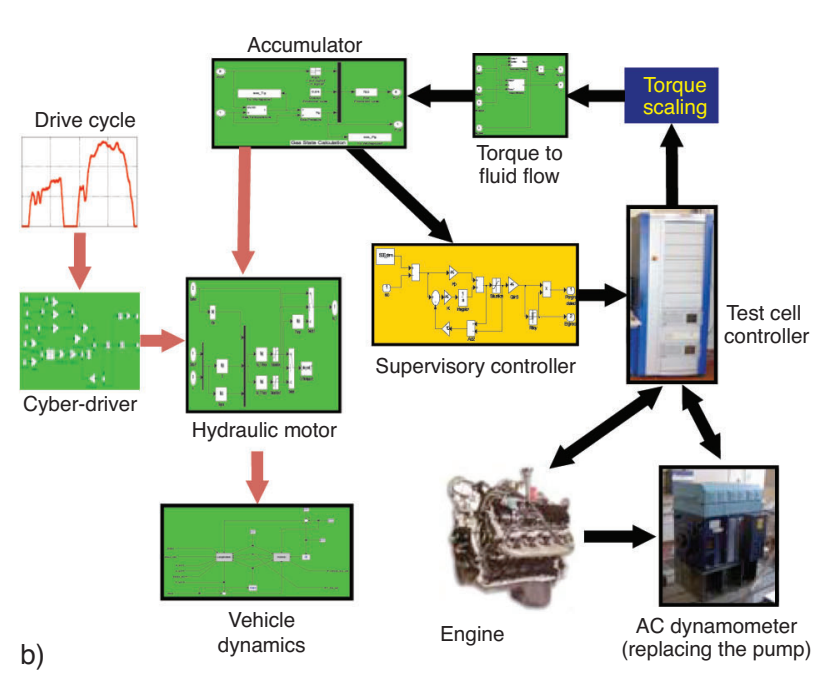

Schematic representation of the a) real SHHV system, and b) EIL setup for the SHHV, with models indicated as SIMULINK blocks, and real components illustrated with pictures. 
the causality of the torque converter model, the implementation of low-pass and lead-lag filtering, and introduction of a preview in the driver model were necessary to resolve the issues related to signal noise, time delay in signal processing, stability and accurate cycle following by the cyber-driver [12]. The prospect of decoupling the engine from the (virtual) wheels, and instead coupling it to a hydraulic pimp/motor with extremely fast response, and application of numerous new models in the hybrid configuration, raise a completely new set of integration challenges.

The schematic representation of the EIL concept for SHHV is given in Figure 8 to facilitate further discussion. As seen in Figure 8 , the setup basically involves two-subsystems, a power-generation and a propulsion subsystem. The propulsion, vehicle and the driver are virtual, represented with models developed or implemented in SIMULINK. On the power-generation side, the hydraulic pump is effectively replaced with the AC Dynamometer. The energy storage integrates the two subsystems in a physical sense; the power-generation module needs to ensure adequate supply of pressurized fluid and maintain the desired SOC in the accumulator under any driving conditions. The supervisory controller is implemented in SIMULINK on the same computer as the component modules. It couples the two subsystems in the controls sense by generating the engine command based on the SOC signal. An additional model is necessary for the full integration, as the torque and speed measured by the dynamometer need to be translated into fluid flow - more in the latter part of this section.

The power-generation control was the first challenge. The solution begins with creation of the engine optimal trajectory in Figure 9 by connecting minimum Brake Specific Fuel Consumption (BSFC) points for every power level. The engine should operate on this line in order to take the maximum advantage of the flexibility offered by the series hybrid architecture. Therefore, the operation of the engine coupled to the hydraulic pump is determined from the intersection of the constant power line and the optimal trajectory. In other words, while the top-level function of the supervisory controller is to determine the engine power request, the additional part of the strategy ensures that the power is provided in a most efficient way. The inverse model is constructed based on experimental data to translate the desired torque into the nominal engine command. In a real vehicle, the $\mathrm{P} / \mathrm{M}_{\mathrm{gen}}$ then operates in a speed control mode to keep the power-generation system running at desired operating conditions. On the EIL setup the dynamometer takes on the same role. To ensure the maximum bandwidth of the engine speed controller, we forgo engine dynamics calculation performed in the EIL setup for the conventional driveline [12], and instead send the desired engine speed directly to the dynamometer system. The built-in dynamometer controller includes the model based dynamometer-inertia compensation that removes up to $70 \%$ of the inertia effect, and this brings its response close enough to what can be expected in a real hydraulic power-generation subsystem.

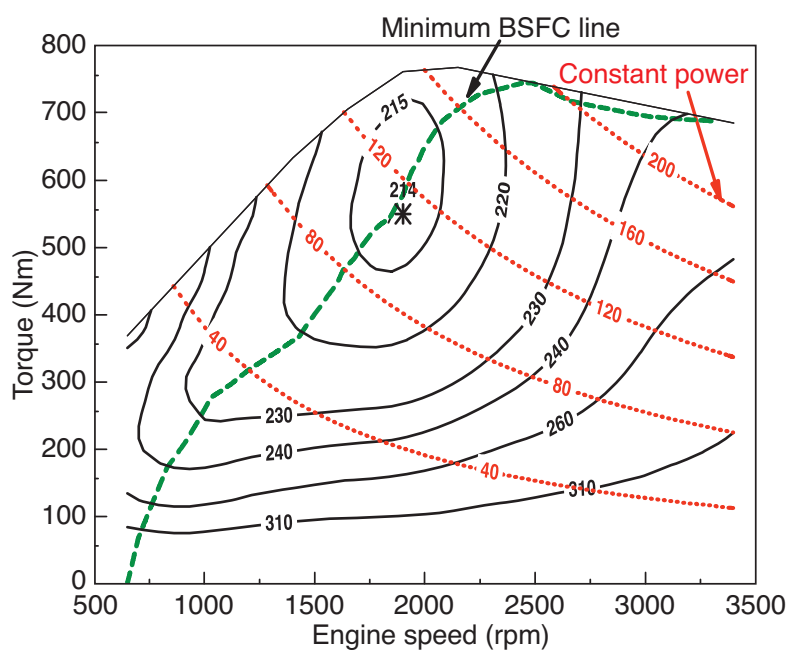

Figure 9

The V8 engine Brake Specific Fuel Consumption (BSFC) map with a best BSFC trajectory (dashed line).

Next challenge was the calculation of the fluid flow into the virtual accumulator based on measurements of real variables in the EIL setup. The flow from the $\mathrm{P} / \mathrm{M}_{\mathrm{gen}}$ cannot be calculated without the displacement factor. To overcome this problem, an inverse $\mathrm{P} / \mathrm{M}_{\text {gen }}$ model is derived from Equations $(2,5,6)$ to find the displacement factor directly from the dynamometermeasured torque and speed. In the case of pump operation, a cubic equation of the general form $a x^{3}+b x+c=0$, is derived to provide the following relationship for the displacement factor $x$ :

$$
\begin{aligned}
T_{a}=\Delta p D|x| & +C_{v} S \Delta p D+C_{f} \Delta p D+C_{h} \sigma^{2} \Delta p D|x|^{3} \\
a & =C_{h} \sigma^{2} \Delta p D \\
b & =\Delta p D \\
c & =C_{v} S \Delta p D+C_{f} \Delta p D-T_{a}
\end{aligned}
$$

Only one of the solutions of Equation (7) provides a real value for $x$, i.e.:

$$
\begin{aligned}
& x_{1}=\frac{1}{6 a} \sqrt[3]{\left((-108 c+12 \sqrt{3}) \sqrt{\frac{4 b^{3}+27 a c^{3}}{a}}\right) a^{2}} \\
& 2 b \\
& \sqrt[3]{\left(-108 c+12 \sqrt{3} \sqrt{\frac{4 b^{3}+27 a c^{3}}{a}}\right)} a^{2}
\end{aligned}
$$

and Equation (9) is used for further calculations. Simply, the calculated $x$ is now implemented in equations for flow and the pump losses to determine the value that should be passed 
on to the accumulator model. In the case there is a desire to evaluate the effect of engine downsizing, a torque scaling model can be added too (see Fig. 8), but only if we are confident that the new engine design guarantees similitude.

Finally, measured signals are susceptible to the noise and communication time delay. These two problems are solved through the introduction of low-pass filtering to eliminate the sensor noise and lead filtering to counter-balance the phase lags introduced by the communication time delays $[44,45]$.

\section{OPTIMIZATION OF DESIGN AND OPERATING MODES IN A $4 \times 4$ VEHICLE}

The initial estimates of the hydraulic accumulator and pump/motor sizes, and the engine displacement, are based on the critical vehicle performance requirements. For example, the $\mathrm{P} / \mathrm{M}_{\text {gen }}$ should be big enough to absorb the maximum engine power at minimum fluid pressure; the $\mathrm{P} / \mathrm{M}_{\text {prop }}$ size should be big enough to satisfy vehicle performance constraints etc. However, finding the best combination of multiple design parameters in the high-degree of freedom system is beyond the abilities of engineering intuition. An optimization algorithm is needed to find design parameters for maximum fuel economy while satisfying the vehicle performance constraints. The constraints are determined from standard fleet requirements and baseline conventional vehicle performance, e.g.:

- continuous speed at $2 \%$ grade: $>55 \mathrm{mph}(88.5 \mathrm{~km} / \mathrm{h})$;

- continuous speed at $3 \%$ grade: $>45 \mathrm{mph}(72.4 \mathrm{~km} / \mathrm{h})$;

- acceleration: $0 \sim 50 \mathrm{mph}(80.5 \mathrm{~km} / \mathrm{h})<10.8 \mathrm{~s}$ (initial SOC $=1$ );

- vehicle speed error during the cycle: $\max 1 \mathrm{mph}(1.6 \mathrm{~km} / \mathrm{h})$ over 1 second interval.

The design optimization framework is setup using the general-purpose Nonlinear Sequential Quadratic Programming (NLSQP), similarly to the procedure proposed by Filipi et al. [10]. The algorithm attempts to minimize the fuel consumption, and every function evaluation requires execution of the vehicle system simulation over a complete driving schedule. The gradient-based NLSQP optimization cannot guarantee finding the global optimum; therefore a multiple-starts method is applied. The starting points are selected using a design-of-experiments methodology in order to distribute them evenly in the design space [10]. It should be noted that a baseline thermostatic supervisory controller was used throughout the optimization exercise - details are provided in the next section.

The list of design variables includes sizes of all hydraulic pump/motors, the accumulator volume and the gear ratio of the two-speed transmission added to the $\mathrm{P} / \mathrm{M}_{\text {prop}}$. The engine size is considered as well, since the flexibility of engine control in a series system allows utilizing full engine power regardless of instantaneous vehicle speed. Indeed, the preliminary study of the SHHV system with a V8 engine predicted improvement of the $0-50 \mathrm{mph}(80.5 \mathrm{~km} / \mathrm{h})$ acceleration time from 10.8 seconds for the conventional vehicle to 9.5 seconds for an SHHV. Clearly, even 10.8 seconds is remarkable performance for a truck of this size, thus it is reasonable to emphasize the fuel economy and downsize the engine to roughly $75 \%$ of the baseline. This matched the acceleration of the conventional super-HMMWV. Consequently, the final optimization was carried out with the V6 engine having the same design and displacement per cylinder as the V8.

The optimization results led to the following set of design parameters: front motor displacement $154 \mathrm{~cm}^{3}$, rear motor displacement $134 \mathrm{~cm}^{3}$, pump $\left(\mathrm{P} / \mathrm{M}_{\text {gen }}\right)$ displacement $194 \mathrm{~cm}^{3}$, final gear ratio 1.87 and accumulator volume of $0.086 \mathrm{~m}^{3}$. All optimization runs converged on higher displacement of the front motor than the rear, thus emphasizing the significance of effective regeneration. The vehicle mass is estimated at each optimization run based on changes of the hydraulic component size. The total SHH vehicle mass estimate for a final configuration is $5228 \mathrm{~kg}$ - a $116 \mathrm{~kg}$ increase compared to the conventional vehicle.

The $4 \times 4$ vehicle propulsion raises the question about the number of propulsion motors. The flexibility attained with two propulsion motors coupled to the front and rear axle is attractive, as it enables their sequential operation. If only the rear motor is used during acceleration instead of the larger single motor, it will operate at a much higher load. High load is favorable, since relative losses diminish and efficiency increases. The front motor will supplement the torque in an extreme case. Conversely, only the front motor can be used for regenerative braking, and the rear and/or friction brakes will supplement as needed. The illustration of the effect of using simultaneous $v s$. sequential operation of the two propulsion motors is given in Figure 10. If the total propulsion power shown in Figure 10b is provided by a single motor or two motors operating simultaneously, its displacement factor (i.e. "command"), fluctuates around a moderate value (see Fig. 10c) during the first part of Federal Urban Driving Schedule (FUDS). If however two motors are used sequentially, the rear motor command during acceleration will be much higher, often reaching full 100\% (see Fig. 10d). The front motor provides assist only during hard acceleration ( $\sim 175-280$ s). During braking, the displacement factor command for the front motor is typically less than -0.5 .

Figure 11 illustrates the cumulative effect of the sequential operation on the fraction of total operating time within the individual load intervals. Clearly, the distributions shift towards higher loads for both the front and the rear P/Ms. Moving the operating points to higher load comes with a significant improvement of instantaneous efficiency, and this enables an additional $10 \%$ improvement of the fuel economy over a complete driving schedule. The sequential logic will be used over the road only, and it will easily be switched to simultaneous operation for off-road driving. 

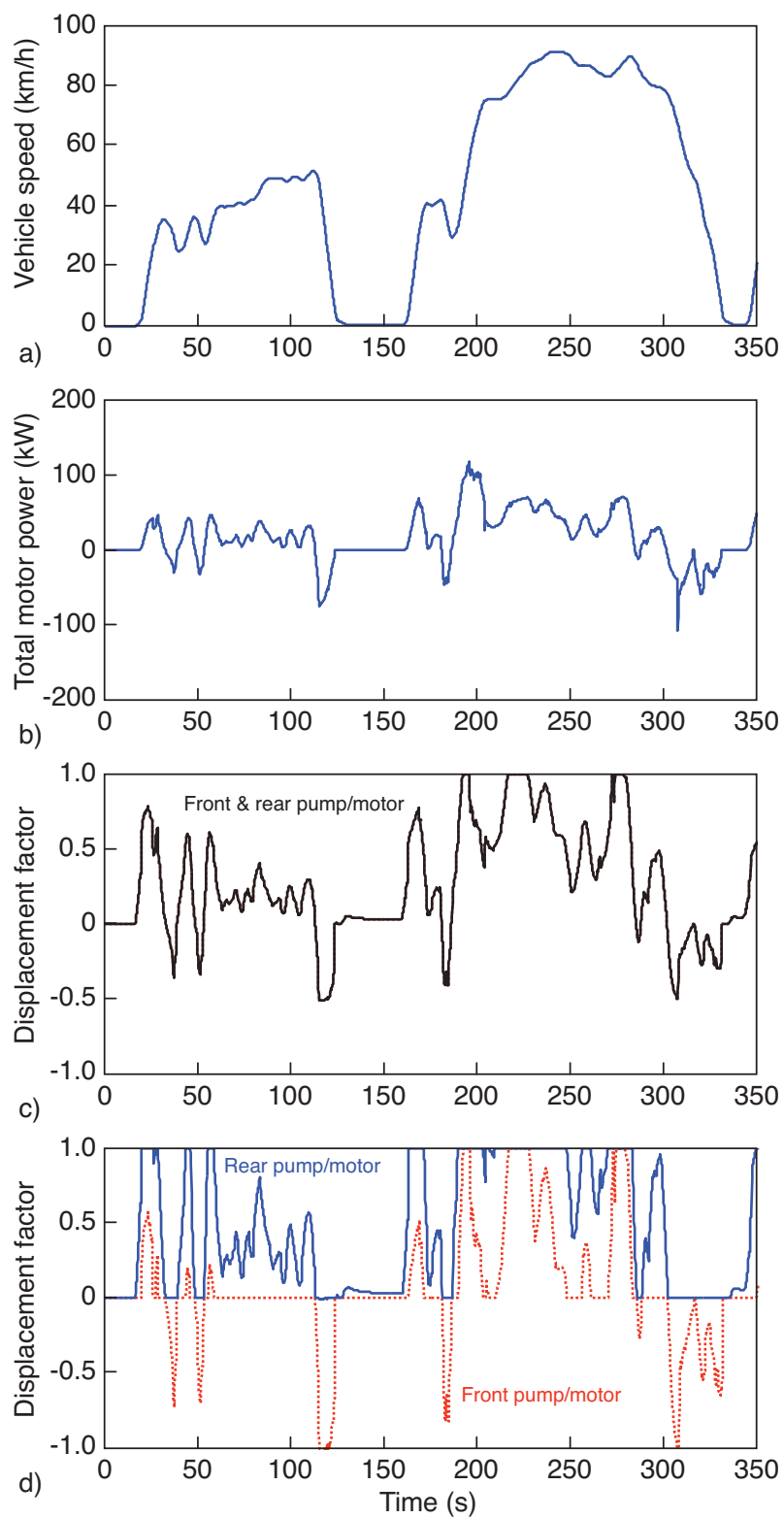

Figure 10

Comparison of the two modes of operating a hydraulic propulsion system with two motors: a) vehicle speed, first 350 seconds of the FUDS, b) total propulsion power, c) torque command for simultaneous operation of two motors, and d) torque commands for sequential operation of two motors.

\section{SERIES HYDRAULIC HYBRID SUPERVISORY CONTROL OPTIONS}

The supervisory control has a profound impact on hybrid system behavior and its ultimate benefits. Therefore, a number of methodologies have been proposed for development of control strategies, ranging from rule-based [46], to Equivalent Consumption Minimization Strategy [47], fuzzy
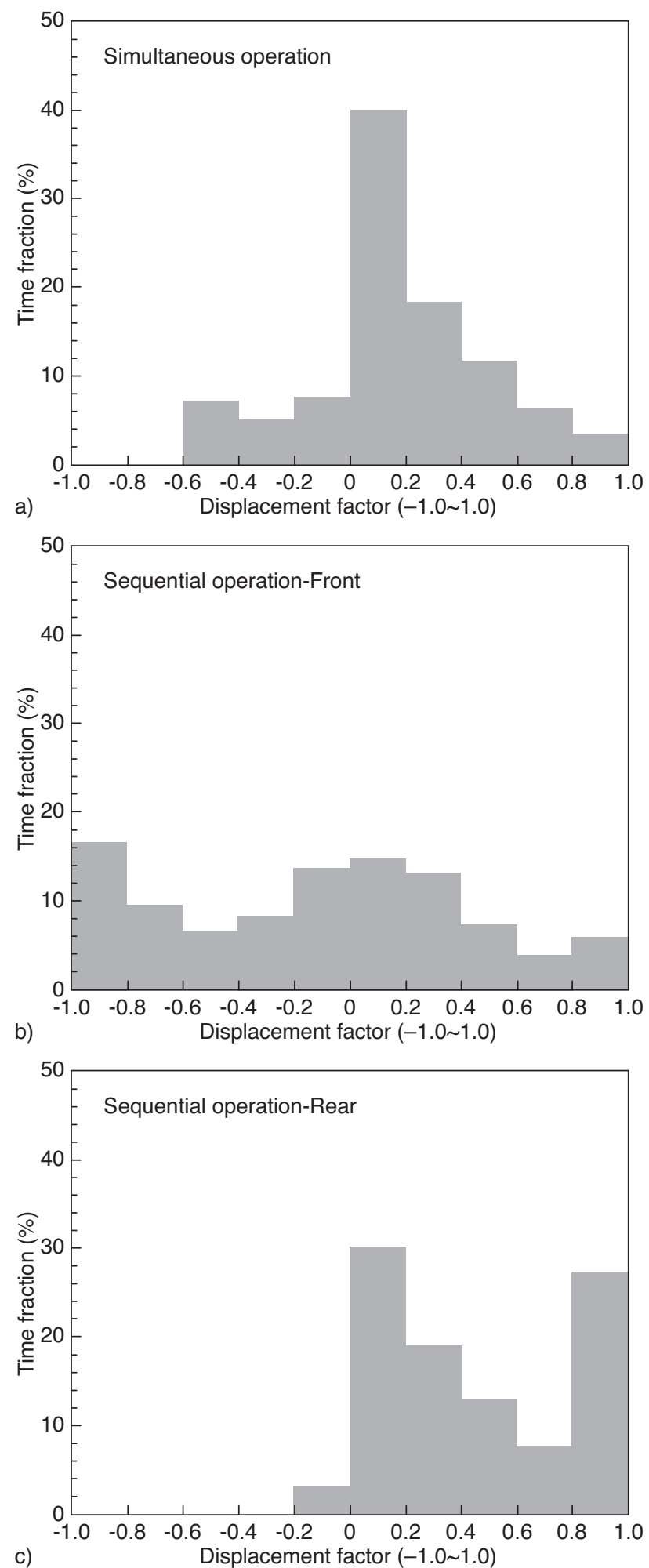

Figure 11

Fraction of the total operating time during a federal city driving schedule spent within discrete displacement factor intervals. Comparison of the results obtained with a) simultaneous motor operation, b) sequentially operated front pump/motor and c) sequentially operated rear pump/motor. 
logic [48, 49], or horizon optimization [31, 32, 50, 51]. The nature of the series hybrid system, with the engine decoupled from the wheels, allows significant freedom in designing the supervisory control strategy. This creates a special challenge when it comes to application of advanced algorithms, since the typical power-split problem is replaced with a decision about controlling the SOC. Previous studies of series electric systems basically relied on thermostatic (on-off) engine power management according to the State-Of-Charge (SOC) in the battery $[52,53]$. The primary task is ensuring safe operation regardless of the driver demand and vehicle states, but the ultimate goal is maximizing the fuel economy. The gains are expected from effective regenerative braking and optimization of engine operation. Since the duration of zero-power intervals can be significant, engine shut-downs are a third factor potentially contributing to the fuel savings. However, the latter requires special measures to ensure continuous operation of accessories and safe vehicle operation [54].

The thermostatic strategy is designed around the conventional wisdom that suggests keeping the engine running at the fuel efficiency "sweet spot". The expectation is that running the engine at a most efficient point will be much more beneficial for the system than load-following dictated by instantaneous propulsion torque requirements. In this section we evaluate the ultimate potential of the thermostatic control strategy through systematic SHHV system analysis. Then we apply the lessons learned to propose an alternative SHHV supervisory control approach and compare the fuel economy and overall system behavior, before moving on to the impact on emissions presented in Section 5.

\subsection{Thermostatic SOC Control}

An intuitive engine-centric approach to development of a top-level strategy is a thermostatic or "bang-bang" control. Whenever the SOC hits the lower limit the engine begins charging the accumulator until reaching the predetermined target value. It is assumed that keeping the engine at the "sweet spot", i.e. in the eye of the BSFC map with lowest specific consumption, will be the best for the fuel efficiency of the system. We question that notion, investigate the effect of threshold power on system behavior and propose the optimal strategy. Operating the engine at the sweet spot is questioned because the fuel economy of the vehicle depends on the system efficiency, rather than component efficiency. As an example, the efficiency of charging depends on pump efficiency as well, and system effects associated with engine dynamic schedules and the length of idling intervals may play a role.

The driver's command is used for controlling the $\mathrm{P} / \mathrm{M}_{\text {prop }}$ power and ensuring that the vehicle follows the desired speed profile. The state of charge is the sole variable used for determining engine power. The engine operating point is then determined from the intersection of the constant power line and the optimal trajectory in Figure 9 . The $\mathrm{P} / \mathrm{M}_{\text {gen }}$ operates in a speed control mode to keep the power-generation system running at desired operating conditions. The particular challenge in developing the power management for a hydraulic hybrid stems from the low energy density of the accumulator. While the battery serves as a huge buffer in the HEV system [53], the accumulator charge undergoes rapid transients and can easily be depleted. In that case the control needs to ensure that the power-generation sub-system directly fulfills the needs of the propulsion system, thus resembling the hydrostatic drive mode.

The basics of the thermostatic SOC control are illustrated with a schematic in Figure 12. As long as the SOC is above the threshold value, e.g. 0.4, the engine power command is zero. When SOC drops to the threshold value, the engine starts charging the accumulator with the predetermined threshold power. The dead band is implemented to prevent frequent turning the engine on or off. Thus, charging continues until the SOC reaches the upper threshold. If power required for propulsion exceeds the threshold level, the SOC will instantaneously drop below the lower limit and the engine power will be progressively increased. Further increase in demand essentially keeps the system operating in the hydrostatic drive mode. In the limiting case, during full power acceleration or hill climbing the engine is operated at rated power.

Four parameters fully define the thermostatic control strategy, namely the threshold SOC, the threshold power, the dead band and the SOC at which power command becomes $100 \%$. The threshold SOC and threshold power deserve particular attention. Keeping the threshold SOC relatively low allows enough spare capacity for regeneration during the subsequent braking event. Nevertheless, the limit should be high enough to provide a buffer during a transition to full-load hydrostatic mode and prevent the SOC from dipping down to zero.

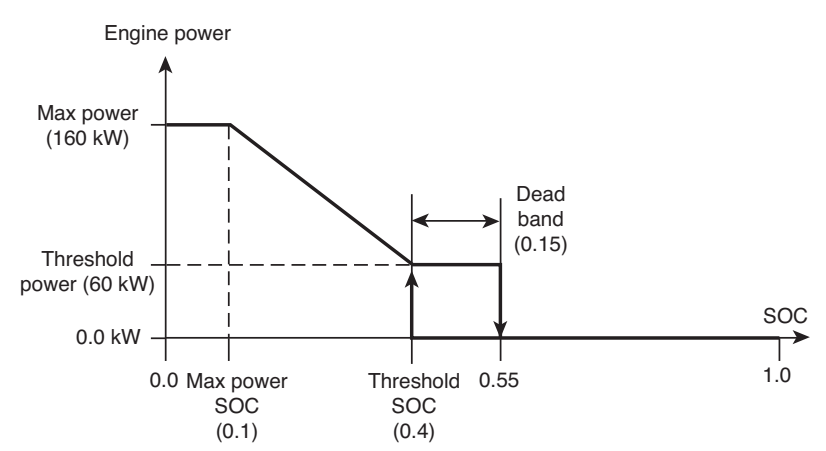

Figure 12

Schematic illustrating the thermostatic SOC power management concept. 

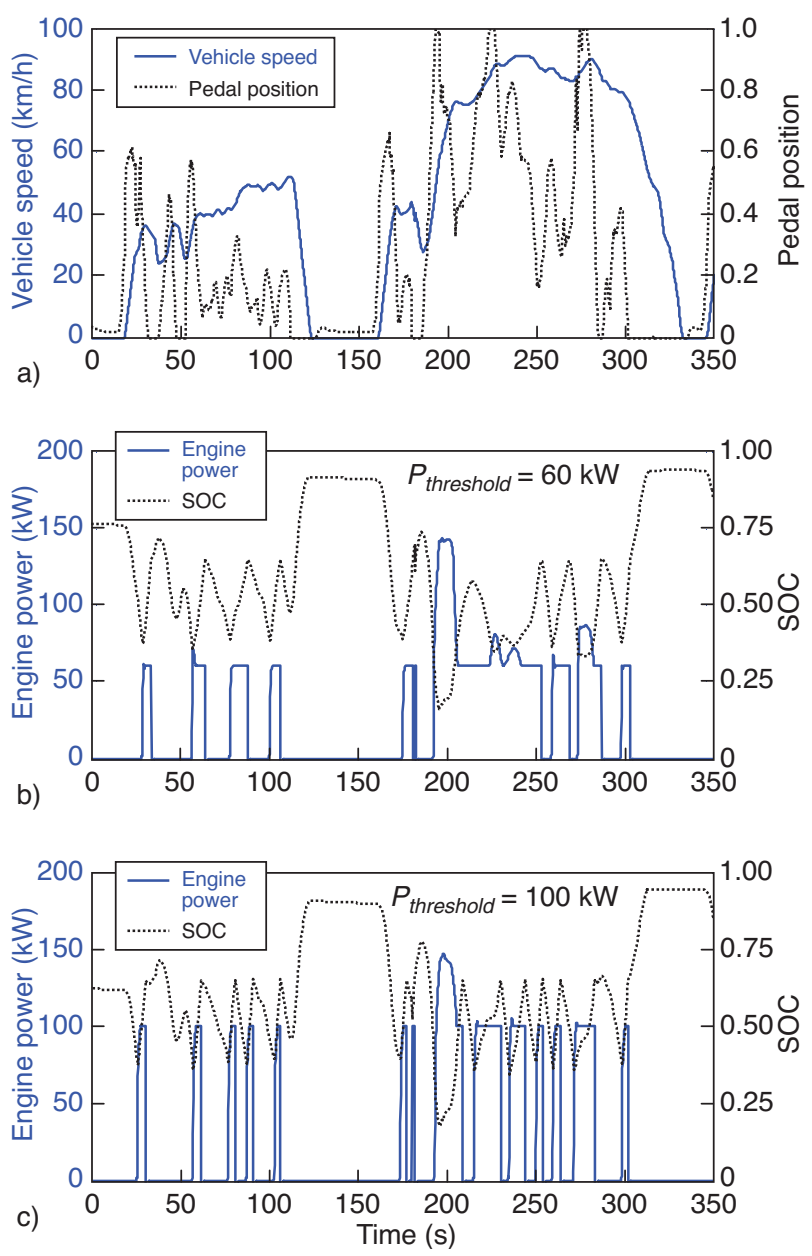

Figure 13

The behavior of the system with a baseline thermostatic SOC control: a) vehicle speed and pedal position history during the first 350 seconds of the FUDS, b) engine power and accumulator state-of-charge for $P_{\text {threshold }}=60 \mathrm{~kW}$, and c) engine power and accumulator state-of-charge for $P_{\text {threshold }}=100 \mathrm{~kW}$.

The effect of threshold power is examined first. The system behavior is expected to be quite different than in the case of the electric hybrid, due to very high output of the pump and relatively low storage capacity of the accumulator. Utilizing the high-fidelity SHHV system simulation generates complete insight and reveals the trends necessary for development of the best strategy. An example of system behavior obtained using the initial guesses for $S O C_{\text {threshold }}$ and $P_{\text {threshold }}$ is given in Figure 13 .

The graph in Figure 13a shows the vehicle speed profile and the pedal position during the first 350 seconds of the FUDS. The pedal position is a command sent directly to the $\mathrm{P} / \mathrm{M}_{\text {prop }}$. Figure $13 \mathrm{~b}$ shows engine power history and SOC with $P_{\text {threshold }}=60 \mathrm{~kW}$, and Figure $13 \mathrm{c}$ shows the same variables for $P_{\text {threshold }}=100 \mathrm{~kW}$. In both cases, i.e. for power threshold of $60 \mathrm{~kW}$ and $100 \mathrm{~kW}$, the thermostatic control strategy keeps the state of charge close to the target value of 0.4 , except during braking and subsequent acceleration. The amplitudes of fluctuating are determined by the dead band, except during hard acceleration when the power demand exceeds the threshold power and SOC instantaneously dips down to $20 \%$. In this case the engine power is increased until the propulsion requirement is fully met. The first braking event rapidly charges the accumulator, and provides most of the energy for the subsequent acceleration, as evidenced by the engine zero-power condition extending through $\sim 175$ seconds.

During the first 150 seconds the engine goes through a typical sequence of on-idle (or on-off) intervals. The switching frequency depends on the threshold power: the charging events become much shorter and more frequent with the increase of $P_{\text {threshold }}$. This hints at profound effects of the control parameters on component duty cycles and vehicle fuel efficiency. Therefore, a full parametric study is conducted to assess the overall impact of $P_{\text {threshold }}$ and $S O C_{\text {threshold }}$ and determine the best values. The effect of each parameter on the vehicle fuel economy was assessed over the FUDS.

Results of the parametric study characterizing the effect of threshold power are given in Figure 14. The upper part (Fig. 14a) illustrates the fuel economy trends with engine shut-downs, and similar values obtained with engine idling throughout the zero-demand periods are given in Figure 14b. The dead band was 0.1 in all cases. Surprisingly, the best values in either case are not obtained for the "sweet spot" (90-100 kW @ 1800 rpm). A much better result is obtained with $P_{\text {threshold }}=60 \mathrm{~kW}$. In the case of engine control with shut-downs this represents a clear maximum. If the engine is allowed to idle, the fuel economy shows slight improvements as the $P_{\text {threshold }}$ is further reduced.

The explanation can be found in Figure 13. The charging events become much shorter and more frequent with the increase of $P_{\text {threshold }}$. Very rapid load transients (e.g. sudden $0-100 \mathrm{~kW}$ increase) come with the penalty, as there is an energy loss associated with rapid engine acceleration. In addition, shortened charging intervals lead to extended idling periods, with a detrimental effect on total fuel consumption. Finally, the higher power output of engine is achieved at higher speed, and that lowers the efficiency of the hydraulic pump. System analysis captures the combined effects and clearly favors charging with a moderate level of power.

Graphs in Figures 14a and b include lines calculated with different threshold SOC values. Lower values are favored, while increasing the $S O C_{\text {threshold }}$ to 0.5 or 0.6 leads to significant reduction of fuel economy. This can be tied directly to the energy storage capacity, i.e. maintaining relatively high values of SOC causes the accumulator charge to reach $100 \%$ before the end of a hard braking event and thus limit the ability to regenerate.

A similar parametric study sheds light on the effect of dead band. The mechanism is very straight forward, since 

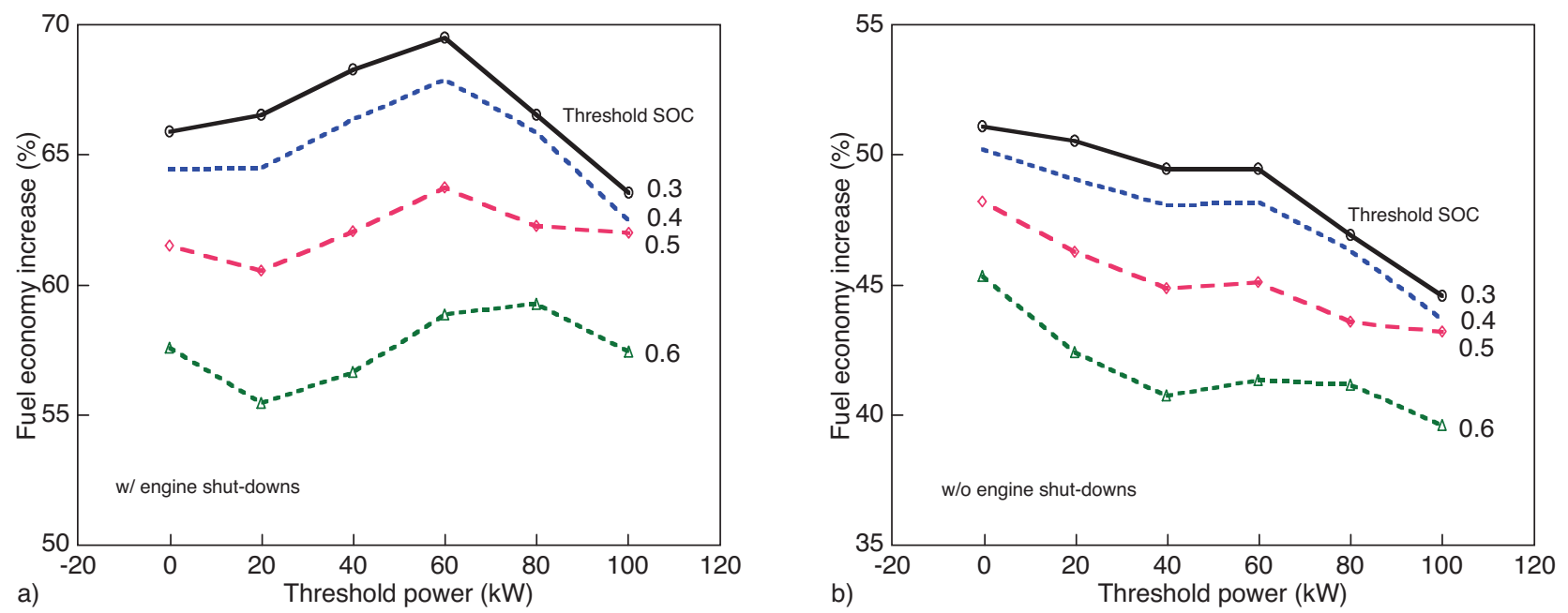

Figure 14

Vehicle fuel improvements as a function of threshold charging power and threshold SOC: a) with engine shut-downs, and b) with engine idling when command $=0$.

increased dead band extends charging events and reduces their frequency. In summary, a combination of the $S O C_{\text {threshold }}$ $=0.3, P_{\text {threshold }}=60 \mathrm{~kW}, S_{\text {O }} C_{\max }=0.1$, and dead band $=0.1$ maximizes the fuel economy of the given system for a 5228$\mathrm{kg}$ vehicle and it is adopted for its final assessment.

\subsection{Modulated SOC Control}

The lessons learned from investigation of the thermostatic SOC control are:

- operating the diesel engine at the "sweet spot" is not necessarily the best for the SHHV fuel economy, due to the effects on engine transient schedules and pump efficiency;

- maintaining a low $S O C_{\text {threshold }}$ maximizes the benefits of regeneration.

The experience with the EIL experimentation using a conventional vehicle model indicates significant impact of rapid engine transients on the particulate emission (see Fig. 7). Combining the lessons learned motivates development of an alternative, modulated SOC control scheme.

With the modulated control, the energy generated by the engine is used directly by the $\mathrm{P} / \mathrm{M}_{\text {prop }}$, thus bypassing the accumulator and maintaining the target SOC during normal driving. The unnecessary energy conversions are avoided. As a result, the modulated control is close to the load-following concept, but the hydraulic accumulator filters the high frequency vehicle power demand, and allows the engine to operate smoother. The penalty associated with running the diesel engine at partial loads should be much less than the system gains, based on the experience with the thermostatic SOC control.

The modulated strategy control uses SOC feedback and Proportional-Integral (PI) controller. The target SOC needs to be high enough to guarantee the vehicle mobility and to be low enough to allow absorbing the maximum braking energy for a given accumulator size and duty cycle. The normalized engine power signal changes between zero and one, and it is determined from:

$$
\begin{aligned}
\frac{P_{\text {eng, demand }}}{P_{\text {eng, } \max }} & =K_{p}\left(S O C_{\text {target }}-S O C_{\text {current }}\right) \\
& +K_{i} \int\left(S O C_{\text {target }}-S O C_{\text {current }}\right) d t
\end{aligned}
$$

where $P_{\text {eng, demand }}$ is the engine power demand, $P_{\text {eng, } \max }$ is the rated engine power, $S O C_{\text {target }}$ is the target SOC, $K_{p}$ is a proportional gain and $K_{i}$ is an integral gain. The anti-windup scheme is used to remove the saturation of the integration error.

The controller performance is tuned by the proportional and integration gains. Finding suitable gains is a relatively subjective and time-consuming process. The first set of values was determined using the pure SHHV simulation, but subsequent EIL tests showed increased overshoots and oscillations due to unexpected noise and delays resulting from the response of real actuators. Therefore, tuning the controller based on EIL work proved to be much more reliable, and that is how the final values were chosen.

The modulated control in the SHHV system displays four different modes. Firstly, when the accumulator SOC is high enough, only accumulator energy is used to drive the vehicle until the SOC approaches the target value. This mode happens at vehicle launch after a braking event that charged the accumulator. The engine power demand and $\mathrm{P} / \mathrm{M}_{\mathrm{gen}}$ power are zero.

The second mode is initiated as the SOC approaches the target value and the controller engages the engine to fulfill 
part of the vehicle power demand. This mode is very dependant on the tuning of the gains in the controller. It represents the transition from the hydraulic-only drive to the hydrostatic drive. Third mode occurs when the SOC is maintained at target SOC and only the engine power is used to drive the vehicle. The fluid flow generated from $\mathrm{P} / \mathrm{M}_{\mathrm{gen}}$ is equal to the consumption of the $\mathrm{P} / \mathrm{M}_{\text {prop}}$, just like in a hydrostatic transmission.

Fourth mode occurs only instantaneously, if the driver demand during a transient exceeds the maximum engine power. The accumulator energy level is allowed to drop instantly to a pre-determined minimum SOC. The latter is designed to prevent cavitation and maintain safe operation, and the supervisory controller needs to ensure that this limit is not crossed. When the SOC reaches the minimum SOC, the engine power remains at rated condition and the system is in hydrostatic equilibrium, i.e. mode four transitions into mode three. Figure 15 illustrates variations of engine power depending on the instantaneous value of SOC, therefore enabling a comparison with the thermostatic logic previously shown in Figure 12.

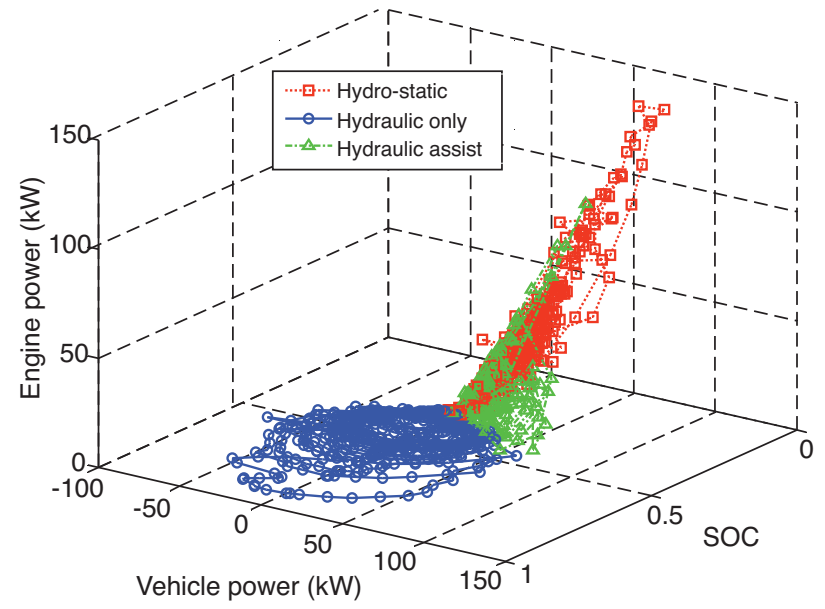

Figure 15

Simulated operating points illustrating the modulated SOC control for a Series HHV in a 3-D graph.

The example of the SHHV system behavior with modulated SOC control is shown in Figure 16. The diesel engine power varies smoothly: the rapid load fluctuations are avoided with proper tuning and thanks to the accumulator acting as an energy buffer. The driver feel would be much improved, because there is a relationship between vehicle power and engine power. This relationship is still softer than in a case of mechanical transmission, as the engine operates on the optimal BSFC trajectory. The target SOC is determined from a tradeoff between driveability and fuel
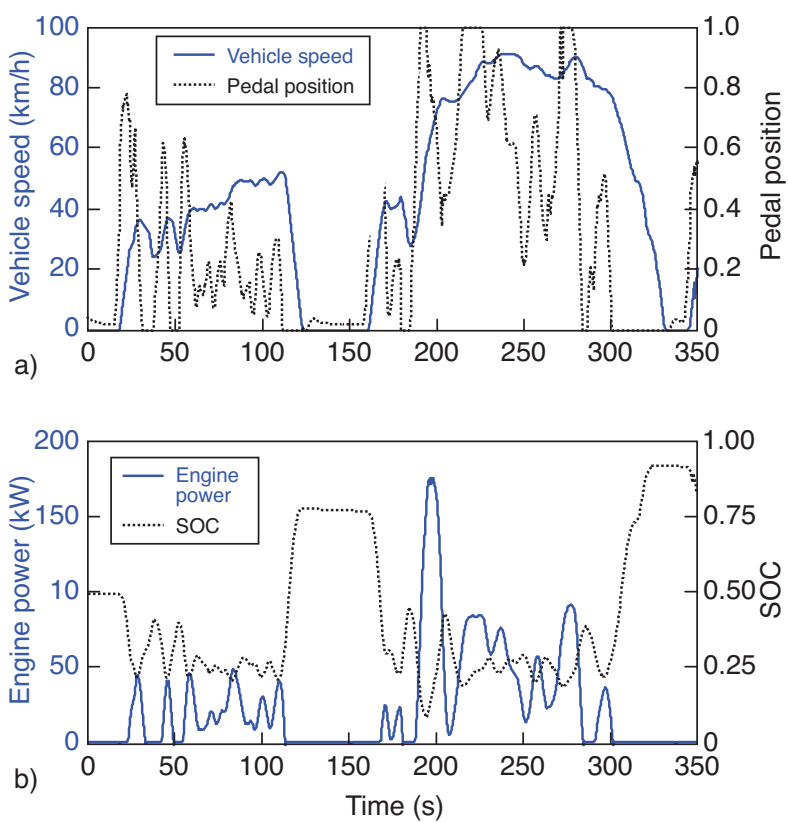

Figure 16

Simulated SHHV system behavior with modulated SOC control: a) vehicle speed and pedal position (driver command) $v s$. time, and b) Engine power and State-Of-Charge during the same interval.

economy. The optimization of design is repeated with the $S O C_{\text {target }}$ as an additional variable, and 0.26 provided a best compromise between fuel economy over the FUDS and performance targets. Figure 16 shows the ability of the PI controller to significantly reduce the SOC fluctuations in the charge sustaining mode when compared to the thermostatic control in Figure 13.

The comparison of the SHHV attributes with two versions of the supervisory control using the EIL is presented in the next section, including the engine-out emissions over the complete driving schedule.

\section{EIL RESULTS: THE FUEL ECONOMY AND LOW-EMISSION POTENTIAL OF THE SERIES HYDRAULIC HYBRID}

This section presents results characterizing the performance, fuel economy and low-emission potential of the Series HHV concept applied to a $4 \times 4$ medium size truck weighing slightly more than 5 tons. The results are all obtained in the Engine-In-the-Loop facility. Therefore, findings related to the fuel economy analysis effectively validate the preceding simulation work. The level of agreement between the predictions and subsequent measurements in the test cell is discussed in the context of the dominant transient behavior with either of the control strategies, i.e. the thermostatic and the 
modulated. Next, the instantaneous particulate emission trends are examined in detail to assess the impact of transients and correlate them to the system behavior dictated by the supervisory control. Finally, the instantaneous traces for both the particulate and $\mathrm{NO}_{\mathrm{x}}$ emissions are integrated to quantify the cumulative emission and benefits attributed to hybridization.

\subsection{Engine Operating Histories and Vehicle Fuel Economy}

The EIL tests provide insight into the real engine system dynamic behavior when coupled to different drivelines, and cumulative effects on fuel economy and emissions. The former are discussed here, and the next section is devoted to emissions trends. The fuel economy evaluations include the results with both the engine idling and engine shut-downs when the power demand is zero. The actual engine-stop and re-start during the driving schedule was not applied at this time, rather the impact of idle-stop on fuel economy is calculated in a post-processor based on the careful experimental characterization of the starting event. The starting fuel consumption, $\mathrm{NO}_{\mathrm{x}}$ and particulate emissions measured in the preliminary test indicate benefits whenever the idle period is longer than 10 seconds.

The detailed insight into the effect of hybridization and a choice of supervisory control on engine fuel consumption is provided in Figure 17, comprised of three BSFC maps with engine visitation points recorded during the EIL tests. Figure 17 a shows the engine behavior in the vehicle with the conventional four-speed automatic transmission, while Figures $17 \mathrm{~b}$ and $17 \mathrm{c}$ illustrate the same for the SHHV with thermostatic SOC control and modulated SOC control, respectively. The color scale indicates the amount of fuel consumed in each region during the US Federal Urban Driving Schedule. The engine operation in the conventional vehicle is scattered around the low-load and mid-speed, where the fuel efficiency is relatively low. A significant amount of fuel is consumed during vehicle stops, when the engine runs at idle speed and works against the losses in the torque converter $(\sim 100 \mathrm{~N}-\mathrm{m})$.

In contrast, the thermostatic controller for the SHHV keeps the engine close to the "sweet spot" during most of the federal urban cycle. Most of the fuel is consumed around the selected $P_{\text {threshold }}=60 \mathrm{~kW}$, as indicated by a red spot in Figure 17b. Hard accelerations increase engine load, and the controller is able to move operating points up the optimal trajectory and into the island of minimum BSFC (large yellow spot). Occasional full-power demand occurs due to engine downsizing. A tangible amount of fuel is still consumed at idle, but at near-zero load. Due to the features of the series system, idling periods are extended but the engine can be shut-down to avoid the penalty. Surprisingly large departures of operating points from the optimal trajectory are observed between idle and $60 \mathrm{~kW}$ line. This is obviously the result of
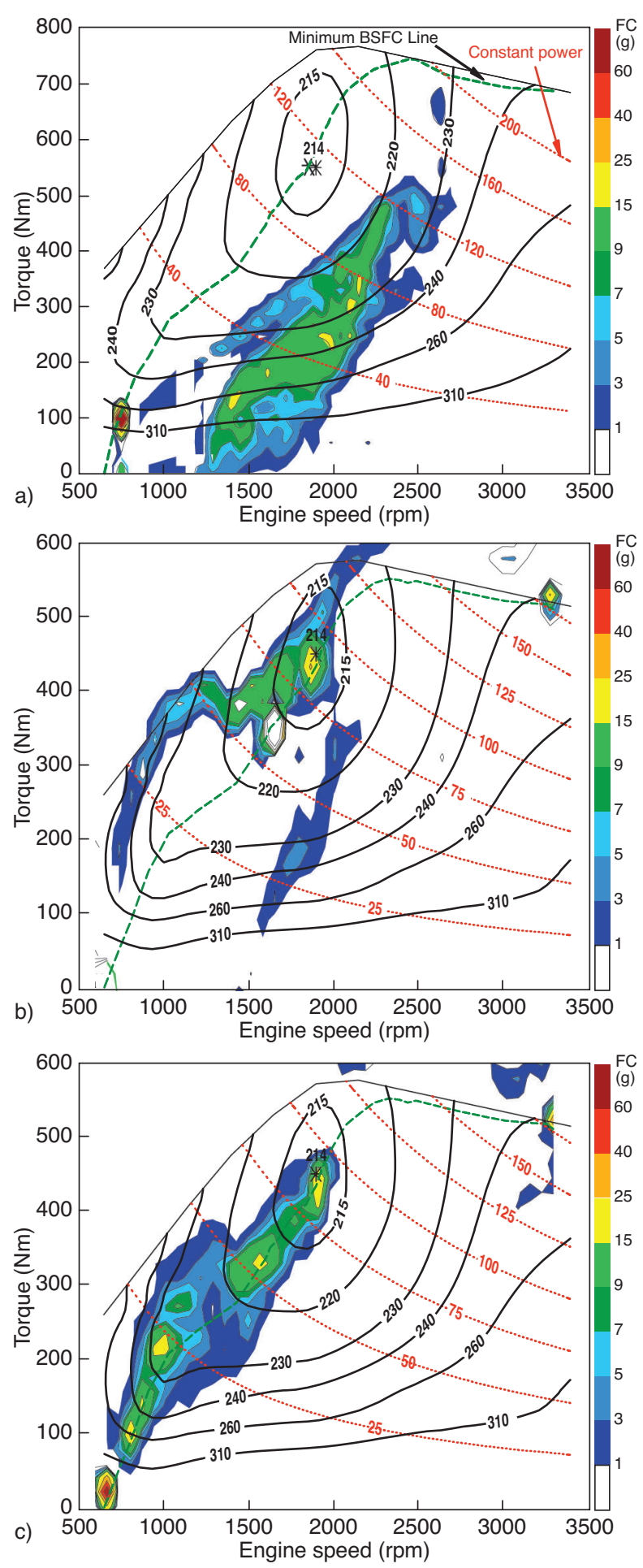

Figure 17

Engine visitation points on the BSFC map, with a color scale indicating the relative amount of fuel consumed in a given zone during FUDS. Comparison of real engine operation in a virtual: a) conventional vehicle (V8 engine), b) series hydraulic hybrid (V6 engine) with a thermostatic SOC controller, and c) series hydraulic hybrid (V6 engine) with a modulated SOC control. 
the engine dynamics with real actuators and it will be discussed in detail in the next paragraph. Finally, Figure 17c indicates success of the modulated SOC controller in keeping the engine close to the optimal trajectory nearly at all times. The points are relatively evenly spread between the near-zero power and $90 \mathrm{~kW}$, with a significant amount of fuel being consumed while engine runs between $25-90 \mathrm{~kW}$. The nearidle operation exhibits the same features as in the case of the thermostatic SHHV control.

The maps in Figures $17 \mathrm{~b}$ and $17 \mathrm{c}$ provide invaluable insight into the impact of supervisory control on engine transients. In the case of the thermostatic control, the engine is forced to frequently go through a step change of load from near-idle to $350 \mathrm{~N}-\mathrm{m} / 1700 \mathrm{rpm}$. Torque demand is further increased to enable engine acceleration. Given the component inertias, and the time-scales of the turbocharger and other actuator responses, the real engine simply cannot respond instantly. Instead, the engine goes through the turbo-lag period, characterized by maximum fueling permitted by the smoke-limiting function in a fuel-injection controller. Therefore, the points between "zero-power" and $60 \mathrm{~kW}$ move significantly up and away from the optimal trajectory. In fact, the power rate-limit of $40 \mathrm{~kW} / \mathrm{s}$ had to be applied in the controller during the EIL tests to ensure stable dynamometer control. The observed departures from the optimal trajectory and power consumed for rapidly accelerating the engine inevitably lead to a fuel economy penalty. The transient engine behavior with a modulated supervisory controller is starkly different, with very mild transients and relatively insignificant departures from the desired BSFC trajectory.

The cumulative impact on vehicle fuel economy over the city driving schedule is given in Table 1 . The series hydraulic Hummer with a $4.5 \mathrm{~L}$ engine and a modulated SOC control improves the fuel economy by $57 \%$ without engine shutdowns and by $72 \%$ with idle-stop compared to the conventional V8 baseline. Interestingly, this is slightly better than the fuel economy measured with the thermostatic control. The penalties associated with harsh and frequent transients in the case of the thermostatic control obviously outweigh the loss of efficiency due to the spread of operating points into the part-load region with modulated control. The diesel engine BSFC variations with torque in the mid-load range are relatively modest, and that's obviously a factor. It should be noted that the observed qualitative trends are representative of the SHHV application to a medium truck, and they might not be universal. Only a repeated application of the proposed methodology, marrying the simulation work, optimization of design and control, and finally the Engine-In-the-Loop integration, will guarantee a reliable answer in case the vehicle configuration/size is changed significantly.

The EIL study was repeated using the highway driving schedule. Details are omitted here for brevity. However, it is worth noting that a very mild nature of the Federal HGWY cycle basically eliminate chances for regeneration. Therefore, the improvements of the fuel economy, in this case $~ 12 \%$ [11] are mainly via optimization of engine operation. Comparisons of relative improvements with hybridization over a city and highway driving schedule give us a sense of the relative contributions. Namely, regeneration is a major factor in impressive benefits over the FUDS, but engine optimization provides a tangible benefit too, in close "competition" with engine shut-downs.

\section{TABLE 1}

Fuel economy and emission determined with Engine-In-the-Loop tests for a vehicle with a conventional driveline, and two versions of the Series Hydraulic Hybrid. The "up" or "down" arrows indicate the direction of percent change with hybridization when compared to a conventional baseline

\begin{tabular}{c|c|c|c}
\hline $\begin{array}{c}4 \times 4 \text { vehicle, } \\
\text { baseline vehicle } \\
\text { weight } 5112 \mathrm{~kg}\end{array}$ & $\begin{array}{c}\text { Conventional } \\
\text { transmission, } \\
\text { V8 engine }\end{array}$ & $\begin{array}{c}\text { Series HHV, } \\
\text { thermostatic } \\
\text { control,V6 w/o } \\
\text { and w/ engine } \\
\text { shut-downs }\end{array}$ & $\begin{array}{c}\text { Series HHV } \\
\text { modulated } \\
\text { control, V6 w/o } \\
\text { and w/ engine } \\
\text { shut-downs }\end{array}$ \\
\hline $\begin{array}{c}\text { Fuel } \\
\text { Economy, EPA }\end{array}$ & 11.2 & $\begin{array}{c}17.0 / 19.1 \\
(51 / 70 \% \uparrow)\end{array}$ & $\begin{array}{c}17.6 / 19.4 \\
(57 / 72 \% \uparrow)\end{array}$ \\
$\begin{array}{c}\text { Urban schedule } \\
(\mathrm{mpg})\end{array}$ & 2.82 & $\begin{array}{c}2.53 / 2.13 \\
(10 / 24 \% \downarrow)\end{array}$ & $\begin{array}{c}2.47 / 2.17 \\
(12 / 23 \% \downarrow)\end{array}$ \\
\hline $\begin{array}{c}\text { NOx }(\mathrm{g} / \mathrm{km}) \\
\text { Soot }(\mathrm{g} / \mathrm{km})\end{array}$ & 0.0865 & $0.0361 / 0.0339$ & $0.0231 / 0.0226$ \\
$(58 / 61 \% \downarrow)$ & $(73 / 74 \% \downarrow)$ \\
\hline
\end{tabular}

\subsection{Particulate and NOx Emission: Transients and Cumulative Effects}

The experience with EIL test using both the conventional and hybrid driveline generally indicate much stronger impact of transients on the particulate emission than $\mathrm{NO}_{\mathrm{x}}$. Therefore, the first part of this section provides insight into the transient phenomena based on measured instantaneous particulate concentration traces. Subsequently, we examine the cumulative $\mathrm{NO}_{\mathrm{x}}$ and soot emission, and estimate the magnitude of the transient contributions to overall drive-cycle emissions.

Figure 18 shows instantaneous particulate concentration in the diesel engine over a representative interval in the FUDS. The traces are obtained by recording a complete sequence of particulate size number-distributions with a differential particulate spectrometer, and subsequently integrating the profiles and estimating the instantaneous mass using methodology explained in [13]. A smoke visibility line is added too. It is typically assumed that the Bosch Smoke Number (BSN) above 2 leads to a visual signature. This is converted using the correlation proposed in [55] to $77 \mathrm{mg} / \mathrm{m}^{3}$. The contour shown in red illustrates a highly transient nature of engine operation in a conventional vehicle with a significant impact on soot concentration trends. The phenomena occurring 


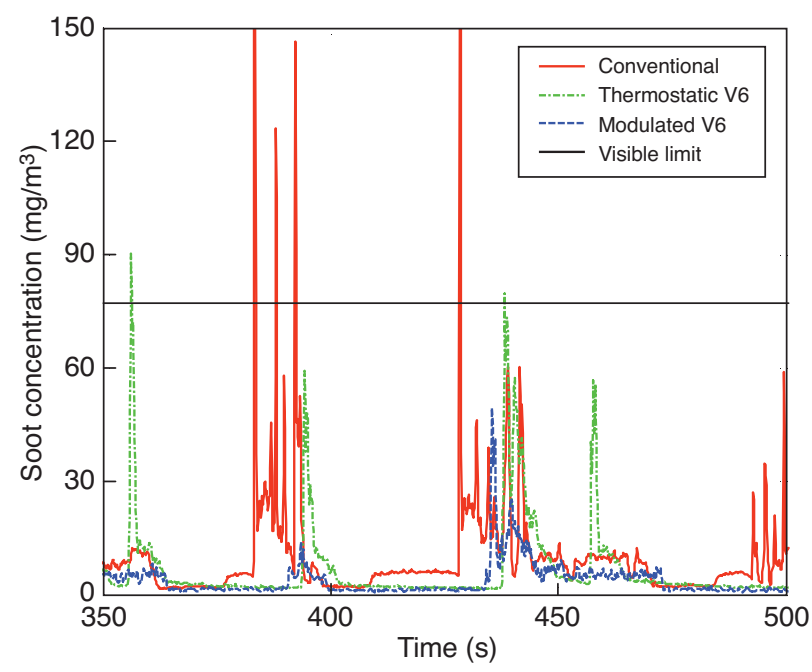

Figure 18

Instantaneous Particulate concentration measurements during the Engine-In-the-Loop test of the diesel engine coupled to three different driveline configurations: the conventional (red), Series HHV with thermostatic control (green) and Series HHV with modulated control (blue). A 350-500 s interval of the EPA urban driving schedule.

during rapid transients and leading to the particle formation illustrated in Figure 7 are discussed in detail in $[12,13]$. For the purposes of the analysis here it is worth noting that the transient spikes of particulate emission are most prominent during sudden acceleration from idle, and they are mostly attributed to the inability of the fuel injection controller to accurately meter the fuel for the very first cycle after a step change, and the impact of both the (high) internal and external residual during the initial stage of turbo-lag [13]. The visibility limit is crossed 25 times.

The interactions in the SHHV system with a thermostatic SOC control are quite different. We can clearly identify the periods of engine high-power operation and idling in between. The harsh transient associated with the change of controller command from "zero" to $P_{\text {threshold }}$ causes a spike in particulate concentration every time the engine is engaged. So, the cumulative emission is expected to be significantly lower, but the visibility line is still crossed relatively frequently (23 times). In contrast, the blue contours in Figure 18 show that SHHV modulated control eliminates most of the spikes and displays mild profiles of soot concentration crossing the visibility limit only once. Such behavior should significantly cut the overall emissions. Indeed, Table 1 shows that the particulate emission of the modulated SHHV is reduced over the city driving schedule by a full $73 \%$. The improvement with the thermostatic control is less due to the frequent transient spikes, but it still represents considerable reduction over the conventional baseline. In case the vehicle is equipped with a Diesel Particulate Filter (DPF), the dynamic loading of the device will significantly depend on the observed transient and cumulative trends. Therefore, the sizing, design and regenerative schedule for the DPF will all benefit in the hybrid configuration.

The impact of optimizing the engine operation in the SHHV on $\mathrm{NO}_{\mathrm{x}}$ emission is also beneficial, but the relative magnitude of improvements is smaller. The reductions are similar with either of the SHHV control strategies, $~ 10 \%$ if engine is allowed to idle, and $\sim 24 \%$ with engine shut-downs. It can be hypothesized that the $\mathrm{NO}_{\mathrm{x}}$ emission reduction stems primarily from reduced amount of fuel burned rather than favorable operating regimes, as the engine actually runs at relatively higher loads in the hybrid.

The final point related to EIL tests is the assessment of the differences between the measurements on the real engine and the predictions obtained previously with pure simulation. Therefore, we compare the predictions of fuel economy and emissions to EIL measurements in Table 2. The predicted emissions are based on simulated speed/load traces and "static look-up tables", i.e. steady-state measurements. In other words, the estimated cumulative values are obtained assuming that the engine marches through transients in a quasisteady manner. The measured values are cumulative numbers obtained after a complete FUDS test.

TABLE 2

Percent differences between simulation predictions and values measured during EIL FUDS tests, without idle-stop

\begin{tabular}{l|c|c|c}
\hline & $\begin{array}{c}\text { Fuel economy } \\
\text { measured (EIL)/ } \\
\text { predicted (\%) }\end{array}$ & $\begin{array}{c}\mathrm{NO}_{\mathrm{x}} \\
\text { measured (EIL)/ } \\
\text { predicted (\%) }\end{array}$ & $\begin{array}{c}\text { Particulates } \\
\text { measured (EIL)/ } \\
\text { predicted (\%) }\end{array}$ \\
\hline $\begin{array}{l}\text { Baseline } \\
\text { conventional } \\
\text { w/ V8 }\end{array}$ & -9.5 & -0.7 & 118.3 \\
\hline $\begin{array}{l}\text { Thermostatic } \\
\text { SHHV w/V6 }\end{array}$ & -6.2 & -4.2 & 100.3 \\
\hline $\begin{array}{l}\text { Modulated } \\
\text { SHHV w/V6 }\end{array}$ & -5.2 & -3.7 & 28.1 \\
\hline
\end{tabular}

The fuel consumption and $\mathrm{NO}_{\mathrm{x}}$ emission predictions are in relatively good agreement, with the simulation consistently overpredicting in the range of $5-10 \%$. The fuel economy results come as no surprise, given the already discussed penalties associated with frequent diesel engine transients, including irregular conditions during turbo-lag. The dynamic excursions benefit the $\mathrm{NO}_{\mathrm{x}}$ emissions, since they typically move the engine towards richer operation with more residual [13], and these conditions reduce the formation of nitric oxides. In a stark contrast, the particulate emissions are drastically underpredicted by the simulation. The more dynamic the engine operation is, the higher the discrepancy becomes. The thermostatic SHHV control is characterized with 
frequent engine-on, engine-off events and the transient effects on particulate formation double the real amount compared to quasi-static predictions. The modulated SHHV is on the other end of the spectrum, as the mild engine operation produces a $24 \%$ increase of real particulate emissions over the quasi-static predictions.

In summary, the simulation provides reliable platform for optimization of the hybrid system for the fuel economy objective, but the final results should be verified with EIL and the discrepancies will be higher in case of more dynamic diesel engine operation. The particulate formation is frequently dominated by irregular in-cylinder conditions during rapid transients; hence EIL becomes an essential tool if optimization objectives include the particulate emission target. The relevance of the EIL will become even stronger with further development of aftertreatment systems, as the interactions between the high degree-of-freedom diesels and a multi-component aftertreatment system creates a multidimensional space, with competing effects from phenomena occurring on very different time-scales. As an example, the hybrid supervisory control will directly affect the time-history of the exhaust gas mass, composition and temperatures, and the actual state of the catalyst will depend on its thermal response, location in the system, and a possible regeneration schedule. Coordinating this while the engine is also going through multiple shut-downs and restarts will require all available tools, but the EIL has a clear advantage in its ability to combine complete diagnostics with the flexibility of hybrid system design/control optimization.

\section{CLOSING COMMENTS AND OUTLOOK}

The vision presented in this work emphasizes the need to develop key methodologies, and then utilize them in a synergistic way in order to truly maximize the potential of a given hybrid vehicle configuration. The system effects, i.e. interactions between components, typically overshadow the impact of optimized operation of a single component, and caution against a component-centric approach to supervisory control development. Instead, complex interactions need to be captured with a predictive hybrid system simulation, and the transient effects on diesel engine fuel economy and emissions explored with the Engine-In-the-Loop facility. An example analyzed in this paper, i.e. the more favorable performance of the SHHV with modulated control vs. the thermostatic (more intuitive) control illustrates the complexity of the effects, and motivates further effort. The next frontier, being pursued with on-going work, is application of policy optimization algorithms for development of an implementable strategy based on multiple objectives. The Deterministic Dynamic Programming (DDP) has been proven to provide an optimal benchmark for controlling the non-linear system when applied to the parallel HEV and
HHV or power-split electric hybrid [8, 31, 50, 56]. A Stochastic Dynamic Programming (SDP) includes probability of driver action and produces a directly implementable policy [57], but again, it has so far been applied only to parallel HEV $[12,57,58]$.

In the hybrid propulsion architectures, the essential part of the policy is a decision about splitting the vehicle power demand between the engine and the alternative power source (battery/accumulator-motor). A "soft" connection between the power-generation subsystem and a propulsion subsystem in a series hybrid presents a fundamentally new challenge in applying the algorithm. In addition, part of the challenge for the hydraulic hybrid application is the low-inertia pump and low energy-density accumulator, which will inevitably lead to highly-dynamic behavior that could be impractical and diminish the returns. Therefore, the implementation of DDP and SDP to a series HHV will require a modified approach, but it will offer a chance to explore a possible hidden "reserve" that the algorithms might uncover.

\section{CONCLUSIONS}

This study presents a multi-step methodology for maximizing the fuel economy and low-emission potential of the Series Hydraulic Hybrid system. The methodology comprises:

- development of the physics-based SHHV system simulation tool;

- coupling of the simulation to an optimization framework for determining the best combination of the SHHV design parameters;

- development of the supervisory control through detailed study of system interactions, and finally;

- coupling of the virtual driveline/vehicle with a real engine diesel engine in the test cell and running the Engine-Inthe-Loop.

The latter enables validation of the fuel economy predictions, evaluation of the diesel engine response with real actuators, and generating insight about the impact of transient engine operation on particulate and $\mathrm{NO}_{\mathrm{x}}$ emissions. Previous studies have shown that dynamic engine operation and response of the fuel injection, turbocharging and EGR systems can lead to transient spikes of particulate emission and be a significant factor in overall vehicle emissions. Therefore, the insight generated with EIL investigations brings complex real phenomena, which cannot be easily captured with the simulation, into the supervisory controller development process.

The vehicle studied here was a $4 \times 4$ off- and on-road truck weighing slightly more than $5000 \mathrm{~kg}$, with a V8 6L Turbocharged DI diesel engine. The conventional baseline has a four-speed automatic transmission. The series HHV configuration removes the mechanical driveline and instead applies a hydraulic motor to the front and the rear axles, 
couples a hydraulic pump to the engine for power generation and utilizes a hydro-pneumatic accumulator for energy storage.

The hybrid system analysis begins with development physics-based models and their integration into a complete vehicle simulation in SIMULINK. The simulation is utilized for analyzing the modes of operation with a $4 \times 4$ configuration, and the results indicate a tangible benefit of operating the propulsion motors sequentially, due to shifting of operating points into higher efficiency regions. Next, the simulation was coupled to an optimization framework in order to determine the best combination of the system design parameters for maximum fuel economy under performance constraints. Multi-starts of the NLSQP ensure the convergence of the derivative-based algorithm (NLSQP) and guide decisions about sizing the components, gear ratios etc. The optimized design led to a $10 \%$ improvement of fuel economy over the initial SHHV configuration.

The objective of the supervisory control development is to command engine operation based on the state-of-charge in the accumulator and maximize the benefits of optimized engine operation and regeneration. The first attempt was based on the engine-centric approach, i.e. a thermostatic control of SOC and conventional wisdom of keeping the engine running at its "efficiency sweet spot". The in-depth system analysis revealed a surprising finding, where the system interactions, such as the very rapid and frequent engine power-up events, outweigh the benefits of running at the "sweet spot". Therefore, reducing the power threshold from $90 \mathrm{~kW}$ to $60 \mathrm{~kW}$ proved to be preferred. The lessons learned, as well as the awareness of the detrimental impact of rapid engine transients on particulate emission, motivated pursuing an alternative, modulated SOC control for the SHHV. A PI controller is designed to allow smoother engine operation, close to the load-following concept, but with benefits of the hydraulic accumulator filtering out the high frequencies in the power demand signal. The modulated control leads to frequent engine part-load operation. Nevertheless, thanks to the fact that the operating points can be kept on the optimal BSFC trajectory and more favorable dynamic interactions in the system, the vehicle fuel economy exceeds the values determined for the thermostatic concept.

The EIL testing provided verification of the fuel economy results and in-depth insight into the effect of transient phenomena on the particulate and $\mathrm{NO}_{\mathrm{x}}$ formation. The discrepancies between predicted and measured fuel economy over a complete driving schedule are higher in case of more dynamic diesel engine transients, but the magnitudes of errors are relatively small; hence, the simulation proves to be a reliable tool for analysis focused only on fuel economy. Similarly, the error in predicting $\mathrm{NO}_{\mathrm{x}}$ was relatively small, less than 5\%. In a stark contrast, the real particulate emissions are more than double compared to a quasi-static model's estimate in the case of conventional vehicle or the hybrid thermostatic SOC control, as the result of spikes in particulate concentration during hard engine acceleration. Milder operation of the engine with the modulated SOC control reduced the error between measurements and predictions considerably. Therefore, EIL becomes an essential tool if the optimization objectives include a particulate emission target. The comprehensive analysis of EIL results led to the selection of the modulated SOC control as the preferred option for the SHHV, with demonstrated $72 \%$ improvement of fuel economy (with engine shut-downs during extended zero-power demand periods), $23 \%$ reduction of $\mathrm{NO}_{\mathrm{x}}$ emission and $74 \%$ reduction of particulate emission when compared to the conventional baseline over the federal urban driving schedule.

\section{ACKNOWLEDGMENTS}

The authors wish to acknowledge the technical and financial support of the Automotive Research Center (ARC) by the National Automotive Center (NAC), and the US. Army Tank-Automotive Research, Development and Engineering Center (TARDEC). The ARC is a Center of Excellence for Automotive Research at the University of Michigan, currently in partnership with the University of Alaska-Fairbanks, Clemson University, University of Iowa, Oakland University, Virginia Tech University, and Wayne State University. Dr. Hosam Fathy is acknowledged for his contribution to vehicle dynamics modeling and integration of the simulation with a test-cell controller, and Josef Mayrhofer of AVL is recognized for technical support with the experimental setup. The authors also wish to acknowledge the technical and hardware support of Dr. Greg Zhang from International Engine and Truck Corporation and John Vanderslice and Kevin Gady from the Ford Motor Company.

\section{REFERENCES}

1 Davis S.C., Diegel S.W. (2004) Transportation Energy Data Book: Edition 24, Center for Transportation Analysis Engineering Science \& Technology Division, Oak Ridge National Laboratory.

2 An F., Vyas A., Anderson J., Santini D. (2001) Evaluating Commercial and Prototype HEVs, SAE paper 2001-01-0951, Warrendale, PA, USA.

3 Folkesson A., Neuman M., Gravesen C. (2008) Targets, Constraints and Rules for Hybrid Management in a Series Hybrid Bus Intended for Commercial Introduction, $S A E$ paper 2008-01-1563, Warrendale, PA, USA.

4 Backe W. (1993) Present and future of fluid power, Proceedings of the Institution of Mechanical Engineers, Part I, J. Syst. Control Eng. 207, 4, 193-212.

5 Environmental Protection Agency (2004) World's First FullSize Hydraulic Hybrid SUV Presented at 2004 SAE World Congress, EPA420-F-04-019.

6 Miller J.M., Everett M. (2005) An assessment of ultra-capacitors as the power cache in Toyota THS-II, GM-Allision 
AHS-2 and Ford FHS hybrid propulsion systems, APEC 2005. Twentieth Annual IEEE Applied Power Electronics Conference and Exposition, IEEE Cat. No. 05CH37646, IEEE 1, 481-490.

7 Alson J., Barba D., Bryson J., Doorag M., Haugen D., Kargul J., McDonald J., Newman K., Platte L., Wolcott M. (2004) Progress Report on clean and Efficient Automotive Technologies under Development at EPA, EPA420-R-04-002, United States Environmental Protection Agency.

8 Wu B., Lin C.-C., Filipi Z., Peng H., Assanis D. (2004) Optimal Power Management for a Hydraulic Hybrid Delivery Truck, J. Vehicle Syst. Dyn. 42, 1-2, 23-40.

9 Buchwald P., Christensen H., Larsen H., Pedersen P.S. (1979) Improvement of City Bus Fuel Economy Using a Hydraulic Hybrid Propulsion System-a Theoretical and Experimental Study, SAE paper 790305, Warrendale, PA, USA.

10 Filipi Z., Louca L., Daran B., Lin C.C., Yildir U., Wu B., Kokkolaras M., Assanis D., Peng H., Papalambros P., Stein J., Szkubiel D., Chapp R. (2004) Combined optimization of design and power management of the hydraulic hybrid propulsion system for the $6 \times 6$ medium truck, Int. J. Heavy Vehicle Syst. 11, 3-4, 372-402.

11 Kim Y.J., Filipi, Z. (2007) Simulation Study of a Series Hydraulic Hybrid Propulsion System for a Light Truck, SAE T.-J. Commercial Vehicles, also presented at the 2007 SAE Commercial Vehicle Engineering Congress \& Exhibition, Chicago, October 2007.

12 Filipi Z., Hagena J., Knafl A., Ahlawat R., Liu J., Jung D., Assanis D., Peng H., Stein J. (2006) Engine-in-the-Loop Testing for Evaluating Hybrid Propulsion Concepts and Transient Emissions - HMMWV Case Study, SAE Paper 2006-01-0443, SAE T.-J. Commercial Vehicles, Warrendale, PA, USA, pp. 23-41.

13 Filipi Z., Hagena J., Fathy H. (2008) Investigating the Impact of In-vehicle Transients on Diesel Soot Emissions, J. Therm. Sci. 12, 1, 53-72.

14 Rakopoulos C.D., Giakoumis E.G., Hountalas D.T., Rakopoulos D.C. (2004) The Effect of Various Dynamic, Thermodynamic, and Design Parameters on the Performance of a Turbocharged Diesel Engine Operating Under Transient Load Conditions, SAE paper 2004-01-0926.

15 Samulski M.J., Jackson C.C. (1998) Effects of Steady-State and Transient Operation on Exhaust Emissions from Nonroad and Highway Diesel Engines, SAE T.-J. Engines $\mathbf{1 0 7}, 982044$.

16 Clark N.N., Gautam M., Rapp B.L., Lyons D.W., Graboski M.S., McCormick R.L., Alleman T.L., Norton P. (1999) Diesel and CNG Transit Bus Emissions Characterization by Two Chassis Dynamometer Laboratories: Results and Issues, SAE T.-J. Fuels Lubricants 108, 1999-01-1469.

17 Hong S.-Ch., Rutland C., Reitz R. (2001) Development of an Integrated Spray and Combustion Model for Diesel Simulations, SAE paper 2001-30-0012, Warrendale, PA, USA.

18 Hong S., Assanis D., Wooldridge M. (2002) Multi-dimensional modeling of $\mathrm{NO}$ and soot emissions with detailed chemistry and mixing in a direct injection natural gas engine, SAE paper 2002-01-1112, Warrendale, PA, USA.

19 Assanis D., Filipi Z., Gravante S., Grohnke D., Gui X., Louca L., Rideout G., Stein J., Wang Y. (2000) Validation and use of SIMULINK integrated, high fidelity, engine-invehicle simulation of the international class VI truck, SAE paper 2000-01-0288, Warrendale, PA, USA.

20 Pourmovahed A., Beachley N.H., Fronczak F.J. (1992) Modeling of a hydraulic energy regeneration system. Part I. Analytical treatment, J. Dyn. Syst.-T. ASME 114, 1, 155-159.
21 Otis D.R., Pourmovahed A. (1985) Algorithm for Computing Non Flow Gas Processes in Gas Springs and Hydro pneumatic Accumulators, J. Dyn. Syst.-T. ASME 107, 1, 53-59.

22 Pourmovahed A., Baum S.A., Fronczak F.J., Beachley N.H. (1988) Experimental Evaluation of Hydraulic Accumulator Efficiency with and without Elastomeric Foam, J. Propul. Power 4, 2, 185-192.

23 Pourmovahed A., Otis D.R. (1990) An Experimental Thermal Time-Constant Correlation for Hydraulic Accumulators, J. Dyn. Syst.-T. ASME 112, 1, 116-121.

24 Louca L., Yildir U.B. (2003) Modeling and Reduction Techniques for Studies of Integrated Hybrid Vehicle Systems, Proceedings of the 4th international Sym-posium on Mathematical Modeling, published in the series ARBESIMReports, ISBN 3-901608-24-9, Vienna, Austria.

25 Fathy H.K., Ahlawat R., Stein J.L. (2005) Proper Powertrain Modeling for Engine-in-the-Loop Simulation, Proceedings of the ASME International Mechanical Engineering Congress and Exposition, November 5-11, Orlando, Florida.

26 Ciesla C.R., Jennings M.J. (1995) A Modular Approach to Powertrain Modeling and Shift Quality Analysis, SAE paper 950419, Special Publication SP-1080.

27 Rizzoni G., Guzzella L., Baumann B. (1999) Unified Modeling of Hybrid Electric Vehicle Drivetrains, IEEE/ASME T. Mechatron. 4, 3, 246-257.

28 Guzzella L., Amstutz A. (1999) CAE-Tools for Quasistatic Modeling and Optimization of Hybrid Powertrains, IEEE T. Vehicular Technol. 48, 6, 1762-1769.

29 Filipi Z., Wang Y., Assanis D. (2004) Variable Geometry Turbine (VGT) Strategies for Improving Diesel Engine InVehicle Response - a Simulation Study, Int. J. Heavy Vehicle Syst. 11, 3/4, 303-326.

30 Fluga E.C. (1993) Modeling of the Complete Vehicle Powertrain Using ENTERPRISE, SAE paper 931179.

31 Lin C.-C., Filipi Z., Loucas L., Peng H., Assanis D., Stein J. (2004) Modeling and Control for a Medium-Duty Hybrid Electric Truck, Int. J. Heavy Vehicle Syst. 11, 3/4, 349-370.

32 Lin C., Filipi Z., Wang Y., Louca L., Peng H., Assanis D., Stein J. (2001) Integrated, Feed-forward Hybrid Electric Vehicle Simulation in SIMULINK and its Use for Power Management Studies, SAE Tech. paper 2001-01-1334.

33 Rousseau A., Sharer P., Pasquier M. (2001) Validation process of a HEV system analysis model: PSAT, SAE paper 2001-01-0953.

34 Markel T., Brooker A., Hendricks T., Johnson V., Kelly K., Kramer B., O'Keefe M., Sprik S., Wipke K. (2002) Advisor: a systems analysis tool for advanced vehicle, J. Power Sources 110, 255-266.

35 Shidore N., Pasquier M. (2005) Interdependence of System Control and Component Sizing for a Hydro-gen-Fueled Hybrid Vehicle, SAE paper 2005-01-3457, Proc. SPIE 6228, 62280E-19, Warren-dale, PA, USA.

36 Kokkolaras M., Louca L.S., Delagrammatikas G.J., Michelena N.F., Filipi Z.S., Papalambros P.Y., Stein J.L., Assanis D.N. (2004) Simulation-based optimal design of heavy trucks by model-based decomposition: An extensive analytical target cascading case study, Int. J. Heavy Vehicle Syst. 11, 3-4, 403-433.

37 Nabi S., Balike M., Allen J., Rzemien K. (2004) An Overview of Hardware-in-the-Loop Testing Systems at Visteon, Proceedings of the SAE World Congress and Exhibition, March 8-11 2004, SAE paper 2004-01-1240, Warrendale, PA, USA. 
38 Tartt C.J., Moskwa J.J. (2001) A hardware-in-the-loop transient diesel engine test system for control and diagnostic development, Proceedings of ASME International Mechanical Engineering Congress and Exposition, 2, pp. 1207-1213.

39 Fleming M., Len G., Stryker P. (2000) Design and Construction of a University-Based Hybrid Electric Powertrain Test Cell, SAE paper 2000-01-3106, Warrendale, PA, USA.

40 Diesel Hybridization and Emissions, Argonne National Laboratory Center for Transportation Research, Report to the DOE from the ANL Vehicle Systems and Fuels Team, http://www.osti.gov/bridge.

41 Partridge W.P., Storey J.M.E., Lewis S.A., Smithwick R.W., DeVault G.L., Cunningham M.J., Currier N.W., Yonushonis T.M. (2000) Time-Resolved Measurements of Emission Transients by Mass Spectrometry, SAE paper 2000-01-2592, Warrendale, PA, USA.

42 Reavell K., Hands T., Collings N. (2002) A fast-response particulate spectrometer for combustion aerosols, SAE paper 2002-01-2714, Warrendale, PA, USA.

43 Park K., Cao F., Kittelson D.B., McMurry P.H. (2003) Relationship between particle mass and mobility for diesel exhaust particle, Environ. Sci. Technol. 37, 3, 577-583.

44 Franklin G.F., Powell J.D., Emami-Naeini A. (1994) Feedback Control of Dynamic Systems, 3rd edition, AddisonWesley.

45 Skogestad S., Postlethwaite I. (1997) Multivariable Feedback Control: Analysis and Design, John Wiley \& Sons.

46 Bowles P.D. (1999) Modeling and Energy Management for a Parallel Hybrid Electric Vehicle (PHEV) with Continuously Variable Transmission (CVT), MS thesis, University of Michigan, Ann Arbor, MI.

47 Paganelli G., Guerra T.M., Delprat S., Santin J.J., Combes E. (2000) Simulation and assessment of power control strategies for a parallel hybrid car, Proc. Inst. Mech. Eng., Part D, $J$. Automobile Eng. 214(D), 705-717.

48 Farrall S.D., Jones R.P. (1993) Energy management in an automotive electric/heat engine hybrid powertrain using fuzzy decision making, Proceedings of the 1993 International Symposium on Intelligent Control, Chicago, IL.
49 Baumann, Bernd M., Washington G., Glenn, Bradley C., Rizzoni G. (2000) Mechatronic design and control of hybrid electric vehicles, IEEE/ASME T. Mechatron. 5, 1, 58-72.

50 Sciarretta A., Guzzella L. (2007) Control of Hybrid Electric Vehicles - A Survey of Optimal Energy-Management Strategies, IEEE Contr. Syst. Mag. 27, 2, 60-70.

51 Sciarretta A., Guzzella L., Onder C.H. (2003) On the Power Split Control of Parallel Hybrid Vehicles: from Global Optimization towards Real-time Control, at Automatisierungstechnik, Vol. 5, pp. 195-203.

52 Caratozzolo P., Serra M., Riera J. (2003) Energy management strategies for hybrid electric vehicles, IEMDC'03, IEEE International Electric Machines and Drives Conference (Cat. No. 03EX679), Madison, WI, USA, 1-4 June, Vol. 1, pp. 241-248.

53 Jalil N., Kheir N.A., Salman M. (1997) A rule-based energy management strategy for a series hybrid vehicle, Proceedings of the 1997 American Control Conference (Cat. No. 97CH36041), Albuquerque, NM, USA, 4-6 June, IEEE 1, 689-693.

54 Filipi Z., Louca L., Stefanopoulou A., Pukrushpan J., Kittirungsi B., Peng H. (2004) Fuel Cell APU for Silent Watch and Mild Electrification of a Medium Tactical Truck, SAE Paper 2004-01-1477, SAE T.-J. Commercial Vehicles 113, 3, 1029-1039, Warrendale, PA.

55 Christian V.R., Knopf F., Jaschek A., Schindler W. (1993) Eine neue Messmethodik der Bosch-Zahl mit erhoehter Empfindlichkeit, MTZ 54, 16-22.

56 Liu J., Peng H. (2006) Control Optimization for a PowerSplit Hybrid Vehicle, Proceedings of the 2006 American Control Conference, Minneapolis, June, pp. 461-471.

57 Liu J., Peng H., Hagena J., Filipi Z. (2008) Engine-in-theloop study of the stochastic dynamic programming optimal control design for a hybrid electric HMMWV, Int. J. Heavy Vehicle Syst.

58 Lin C.C., Peng H., Grizzle J.W. (2004) A Stochastic Control Strategy for Hybrid electric Vehicle, Proceeding of the 2004 American Control conference, Boston, Massachusetts, Vol. 5, pp. 4710- 4715 .

Final manuscript received in February 2009 Published online in September 2009 


\section{APPENDIX}

The following values are used as input data for Hydraulic Hybrid Vehicle simulation studies.

TABLE A1

HWMMV Diesel Engine Specification

\begin{tabular}{l|c|c}
\hline Configuration & V6 & V8 \\
\hline Bore $\times$ stroke (mm) & \multicolumn{2}{|c}{$95 \times 105$} \\
\hline Displacement (L) & 4.5 & 6.0 \\
\hline $\begin{array}{l}\text { Rated power (kW) } \\
@ 3300 \mathrm{rpm}\end{array}$ & 178 & 238 \\
\hline $\begin{array}{l}\text { Maximum torque (Nm) } \\
\text { @2100 rpm }\end{array}$ & 580 & 774 \\
\hline Compression ratio & \multicolumn{2}{|c}{$18.0: 1$} \\
\hline Aspiration & \multicolumn{2}{|c}{ Variable Geometry Turbine (VGT)/ } \\
& \multicolumn{2}{|c}{ Intercooler } \\
\hline Fuel injection system & \multicolumn{2}{c}{ Unit Injector } \\
\hline
\end{tabular}

TABLE A2

Transient Dynamometer Specification

\begin{tabular}{l|c}
\hline Manufacturer & AVL \\
\hline Name & $\begin{array}{c}\text { ELIN series 100 APA Asynchronous } \\
\text { Dynamometer }\end{array}$ \\
\hline Speed range & $\pm 8000 \mathrm{rpm}$ \\
\hline Torque range & -1273 to $+1400 \mathrm{Nm}$ \\
\hline Power (Absorbing/Motoring) & $330 / 300 \mathrm{~kW}$ \\
\hline Rotational inertia & $2.91 \mathrm{~kg} . \mathrm{m}^{2}$ \\
\hline Torque response & $5 \mathrm{~ms}$ \\
\hline Torque reversal & $10 \mathrm{~ms}(-100 \%$ to $100 \%)$ \\
\hline Operating system & AVL PUMA OPEN \\
\hline Input/Output system & AVL Fast Front End Module (FFEM) \\
\hline
\end{tabular}

TABLE A3

HWMMV Driveline Specifications

\begin{tabular}{l|c|c}
\hline & Conventional & Series hybrid \\
\hline T/C Turbine inertia $\left(\mathrm{kg}-\mathrm{m}^{2}\right)$ & 0.2 & - \\
\hline Transmission 1st gear ratio & 3.42 & 3.0 \\
\hline Transmission 2nd gear ratio & 2.26 & 1.0 \\
\hline Transmission 3rd gear ratio & 1.5 & - \\
\hline Transmission 4th gear ratio & 1.0 & - \\
\hline Transmission 1st gear efficiency & 0.94 & 0.96 \\
\hline Transmission 2nd gear efficiency & 0.96 & 1.0 \\
\hline Transmission 3rd gear efficiency & 0.97 & - \\
\hline Transmission 4th gear efficiency & 0.97 & - \\
\hline Differential gear ratio & 3.56 & 1.87 \\
\hline Differential gear efficiency & 0.94 & 0.96 \\
\hline
\end{tabular}

TABLE A4

HWMMV Vehicle Specifications

\begin{tabular}{l|c}
\hline Sprung mass $(\mathrm{kg})$ & 4672 \\
\hline Unsprung mass front $(\mathrm{kg})$ & 220 \\
\hline Unsprung mass rear $(\mathrm{kg})$ & 220 \\
\hline Wheel inertia $\left(\mathrm{kg} \cdot \mathrm{m}^{2}\right)$ & 32.0 \\
\hline Brake viscous damping $(\mathrm{Nms} / \mathrm{rad})$ & 170 \\
\hline Wheel radius $(\mathrm{m})$ & 0.4412 \\
\hline Wheel viscous damping $(\mathrm{Nms} / \mathrm{rad})$ & 4.0 \\
\hline Aerodynamic drag coeff. $(\mathrm{Cd})$ & 0.7 \\
\hline Frontal area $\left(\mathrm{m}^{2}\right)$ & 3.58 \\
\hline Road/tire friction coefficient $(-)$ & 0.7 \\
\hline
\end{tabular}

